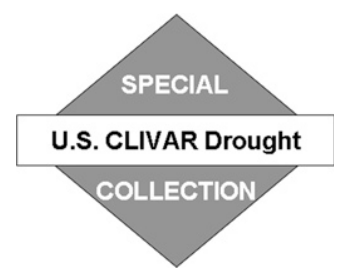

\title{
Relationship between Precipitation in the Great Plains of the United States and Global SSTs: Insights from the IPCC AR4 Models
}

\author{
ANTONIETTA CAPOTONDI \\ NOAA/Earth System Research Laboratory, and University of Colorado/CIRES, Boulder, Colorado \\ Michael A. AleXANDER \\ NOAA/Earth System Research Laboratory, Boulder, Colorado
}

(Manuscript received 15 June 2009, in final form 5 November 2009)

\begin{abstract}
Multicentury preindustrial control simulations from six of the Intergovernmental Panel on Climate Change Fourth Assessment Report (IPCC AR4) models are used to examine the relationship between low-frequency precipitation variations in the Great Plains (GP) region of the United States and global sea surface temperatures (SSTs). This study builds on previous work performed with atmospheric models forced by observed SSTs during the twentieth century and extends it to a coupled model context and longer time series. The climate models used in this study reproduce the precipitation climatology over the United States reasonably well, with maximum precipitation occurring in early summer, as observed. The modeled precipitation time series exhibit negative "decadal" anomalies, identified using a 5-yr running mean, of amplitude comparable to that of the twentiethcentury droughts. It is found that low-frequency anomalies over the GP are part of a large-scale pattern of precipitation variations, characterized by anomalies of the same sign as in the GP region over Europe and southern South America and anomalies of opposite sign over northern South America, India, and Australia. The largescale pattern of the precipitation anomalies is associated with global-scale atmospheric circulation changes; during wet periods in the GP, geopotential heights are raised in the tropics and high latitudes and lowered in the midlatitudes in most models, with the midlatitude jets displaced toward the equator in both hemispheres. Statistically significant correlations are found between the decadal precipitation anomalies in the GP region and tropical Pacific SSTs in all the models. The influence of other oceans (Indian and tropical and North Atlantic), which previous studies have identified as potentially important, appears to be model dependent.
\end{abstract}

\section{Introduction}

The western United States, including the Great Plains (GP), is particularly vulnerable to multiyear droughts. Recent examples during the twentieth century are the decade-long drought of the 1930s, which mainly affected the Great Plains area; the dry period from the late 1940s to the late 1950s in several regions of the southwest; and the several years of reduced precipitation after the demise of the 1997/98 El Niño. During the 1930s, the degree of aridity in the Great Plains area was so severe that all drought-sensitive crops died, and dust storms devastated the area, which became known as the "Dust Bowl."

Corresponding author address: Antonietta Capotondi, NOAA/ ESRL/PSD, 325 Broadway, Boulder, CO 80305.

E-mail: antonietta.capotondi@noaa.gov
Long-term droughts in the American west were not limited to the twentieth century. Paleoclimate evidence (Stine 1994; Cook et al. 2004; Herweijer et al. 2007) indicates that a series of severe droughts occurred in the western United States starting at approximately A.D. 600, and continuing into the fourteenth century, the most probable cause of the abandonment of the ancestral Pueblo Indians sites at the beginning of the fifteenth century (Douglass 1929, 1935; Dillehay 1974; Jones et al. 1999; Benson et al. 2007). This time coincided with the Medieval Warm Period in Europe (A.D. 800-A.D. 1400), indicating that longlasting droughts in the western United States may be associated with global-scale precipitation anomalies (Seager et al. 2007). In particular, dry conditions in western North America tend to be associated with dry conditions across the midlatitude North Atlantic Ocean, the Mediterranean, including parts of Europe and the 
Middle East, and central Asia (Hoerling and Kumar 2003). Sparse paleoclimate evidence also indicates that, when North America is dry, it is wet in northern South America; dry in southern South America, southern Europe and the Mediterranean, and equatorial East Africa; and wet in the Sahel, South Africa, and India (Seager et al. 2007).

Numerical simulations performed with atmospheric models driven by observed sea surface temperatures (SSTs) indicate that the major droughts in the twentieth century are partly driven by subtle changes in tropical SSTs (Schubert et al. 2004a,b; Seager et al. 2005). Schubert et al. (2004a,b) were able to reproduce the Dust Bowl drought as the ensemble average of their SST-forced atmospheric simulations, although there was considerable scatter among the different ensemble members, an indication of the important influence of internal atmospheric variability upon the evolution of precipitation over North America. Sensitivity experiments where SST anomalies were prescribed only in selected regions showed the key role of tropical Pacific SSTs, although the tropical Atlantic can also have a significant contribution in driving precipitation variations over North America. The greatest influences upon dry conditions in the western United States are found when the tropical Pacific is anomalously cold, as during La Niña events, and the tropical Atlantic is warmer than average (Schubert et al. 2004a). Warm conditions in the western tropical Pacific and Indian Ocean can also contribute to dry conditions over the United States (Hoerling and Kumar 2003), as found during the 1998-2002 drought.

More recently, Seager et al. (2008) have shown that ensemble simulations driven by observed SSTs over the 1930s period produced a drought signal over the United States that significantly differed from the model climatology, while the precipitation signal obtained with climatological SST forcing was not statistically distinguishable from the model climatology, supporting the idea that SST forcing can play a significant role in the occurrence of droughts over the central United States and can increase prediction capabilities. Significant correlations between summer precipitation and Pacific SSTs were also noted by Ting and Wang (1997) at interannual time scales.

The SST-forced atmospheric simulations of Schubert et al. $(2004 a, b)$ and Seager et al. $(2005,2008)$ showed that precipitation anomalies in the western United States were part of a global-scale pattern of precipitation changes, consistent with the paleoclimate evidence. The globalscale character of those changes appears to be related to the global-scale atmospheric circulation anomalies, a response to anomalous SSTs similar to that found during El Niño-Southern Oscillation (ENSO) events (Seager et al. 2005). During warm tropical conditions, tropical upper-troposphere geopotential heights are raised, consistent with tropical warming, while heights are lower in the midlatitudes.

The mechanism by which tropical Pacific SST anomalies influence precipitation in the American west involves changes in strength and position of the subtropical jets in both hemispheres and changes in transient eddies and eddy-induced meridional flow (Seager et al. 2005). When the tropical Pacific is cold, the equator-to-pole tropospheric temperature gradient decreases, and the subtropical jet streams weaken and move poleward. The resulting atmospheric adjustment involves an eddy-induced poleward flow, creating areas of mass convergence, where descending motion, responsible for suppressing precipitation, must take place. Changes in tropical Pacific SSTs can also alter the mean atmospheric circulation through changes in the location of the major tropical heating sources.

Meehl and Hu (2006) have examined the relationship between long periods of precipitation deficit in southwestern North America and global SSTs in a 1360-yrlong control integration of the Parallel Climate Model, a fully coupled climate model. The focus of this study was on "megadroughts," defined as 11-yr running mean regional area-averaged negative precipitation anomalies lasting for at least $20 \mathrm{yr}$. A statistically significant correlation was found between the low-frequency evolution of precipitation in the southwestern North America and low-frequency Pacific SST anomalies. The correlation pattern is very similar to the leading mode of Pacific decadal SST variability in the model, which is, in turn, in very good agreement with the spatial pattern of the interdecadal Pacific oscillation (IPO) as described by Power et al. (1999) and Arblaster et al. (2002). This pattern is characterized by anomalies of the same sign in a broad triangular-shaped region centered along the equatorial Pacific, and anomalies of opposite sign in the centralwestern midlatitudes of both hemispheres, and is similar to the Pacific decadal oscillation (PDO) computed by Mantua et al. (1997) over the North Pacific.

In this study we examine the connection between multiyear precipitation anomalies in the western United States and global SSTs in a subset of the climate models developed in support of the Intergovernmental Panel for Climate Change (IPCC) Fourth Assessment Report (AR4). In particular, we are interested in examining whether, and to what extent, the results obtained with ensembles of Atmospheric Model Intercomparison Project (AMIP)-type simulations performed with the same model (e.g., Schubert et al. 2004a; Seager et al. 2005) are found across a suite of fully coupled climate models. The IPCC models differ in both spatial resolution and physical parameterizations in each of their component models but have been run in similar configurations 
TABLE 1. Information about the six climate models used in this study, including country of origin, resolution of the ocean and atmospheric components (lon, lat, vertical), and duration (yr) of the preindustrial control simulations.

\begin{tabular}{llccc}
\hline \hline \multicolumn{1}{c}{ Model } & \multicolumn{1}{c}{ Country } & Ocean resolution & Atmospheric resolution & Duration \\
\hline GFDL CM2.1 & United States & $1^{\circ} \times 0.33^{\circ} \mathrm{L} 50$ & $2.5^{\circ} \times 2^{\circ} \mathrm{L} 24$ & 500 \\
GFDL CM2.0 & United States & $1^{\circ} \times 0.33^{\circ} \mathrm{L} 50$ & $2.5^{\circ} \times 2^{\circ} \mathrm{L} 24$ & 500 \\
NCAR CCSM3 & United States & $1.125^{\circ} \times 0.27^{\circ} \mathrm{L} 40$ & $\mathrm{~T} 85 \mathrm{~L} 26$ & 500 \\
UKMO HadCM3 & United Kingdom & $1.25^{\circ} \times 1.25^{\circ} \mathrm{L} 20$ & $3.75^{\circ} \times 2.5^{\circ} \mathrm{L} 19$ & 341 \\
CSIRO Mark & Australia & $1.875^{\circ} \times 0.84^{\circ} \mathrm{L} 31$ & $\mathrm{~T} 63 \mathrm{~L} 18$ & 380 \\
$\quad$ version 3.0 $(\mathrm{Mk} 3.0)$ & Canada & $1.4^{\circ} \times 0.94^{\circ} \mathrm{L} 29$ & $\mathrm{~T} 63 \mathrm{~L} 31$ & 350 \\
\hline
\end{tabular}

and with similar anthropogenic forcing. For this study we will focus on the preindustrial control integrations (PICNTRL) whose multicentury duration allows a better characterization of multiyear droughts. In addition, since the greenhouse gas concentration is kept fixed at the preindustrial level in the PICNTRL simulations, the relationship between SST and precipitation can be examined in the context of natural climate variability. The specific questions that we ask are 1) is the SSTprecipitation relationship in the climate models consistent with what has emerged from observations and AMIP simulations; 2) is the large-scale signature of drought conditions in the central United States from the IPCC AR4 models in agreement with the evidence from paleoclimate and proxy records, like those described by Seager et al. (2007); and 3) are the SST anomalies associated with central U.S. droughts related to the dominant mode of Pacific SST variability in the different models? Following Schubert et al. (2004a,b), we will focus on the evolution of precipitation in the region of the GP.

The paper is organized as follows: in section 2 we describe the models used for this study as well as the observational datasets used to validate the models; in section 3 we examine the model representation of mean precipitation over North America to assess how reliable the models are; in section 4 the evolution of precipitation over the Great Plains region is considered along with the associated global patterns of precipitation, SST, and atmospheric circulation anomalies. The relationship between the precipitation changes and the leading mode of Pacific SST variations is examined in section 5, and conclusions are provided in section 6 .

\section{Models and data}

We examine the PICNTRL from six of the IPCC climate models, as listed in Table 1. The preindustrial control simulations are multicentury simulations with the chemical composition of the atmosphere fixed at preindustrial conditions. The absence of any anthropogenic forcing in these simulations allows us to focus on natural variability only. The model outputs have been collected at the Program for Climate Model Diagnosis and Intercomparison. The models have been chosen based on the availability of their ocean data as well as the duration of their preindustrial control integrations, which we wanted to be at least $300 \mathrm{yr}$, to better characterize low-frequency precipitation evolution and decadal climate variability. The duration of the PICNTRL simulation for each model is shown in the last column of Table 1. As seen from the second and third column of Table 1, the models differ considerably in both horizontal and vertical resolutions. The numerical grids used by each model are also different. For example, the ocean component of Community Climate System Model, version 3 (CCSM3) is based on the Parallel Ocean Program and uses a bipolar grid with the northern pole displaced over Greenland. Most ocean components have finer meridional grid spacing in the tropics, to resolve the jetlike structure of the equatorial circulation. Physical parameterizations of subgridscale processes, such as convection and mixing, also differ among models.

Because of the coarse horizontal resolution of the atmospheric components of the climate models, the representation of precipitation over North America may be

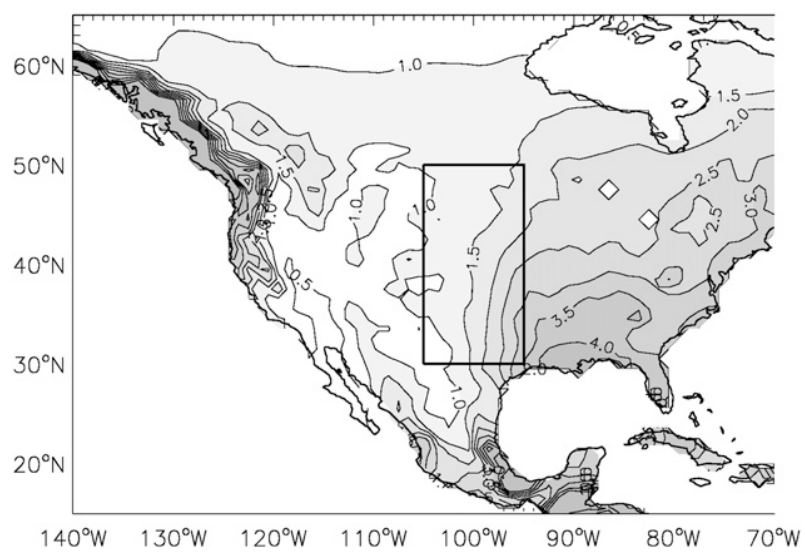

FIG. 1. Annual mean precipitation $\left(\mathrm{mm} \mathrm{day}^{-1}\right)$ over North America from the GPCC dataset. Contour interval is $0.5 \mathrm{~mm}^{\text {day }}{ }^{-1}$. Values greater than $1 \mathrm{~mm}$ day $^{-1}$ are shaded. 

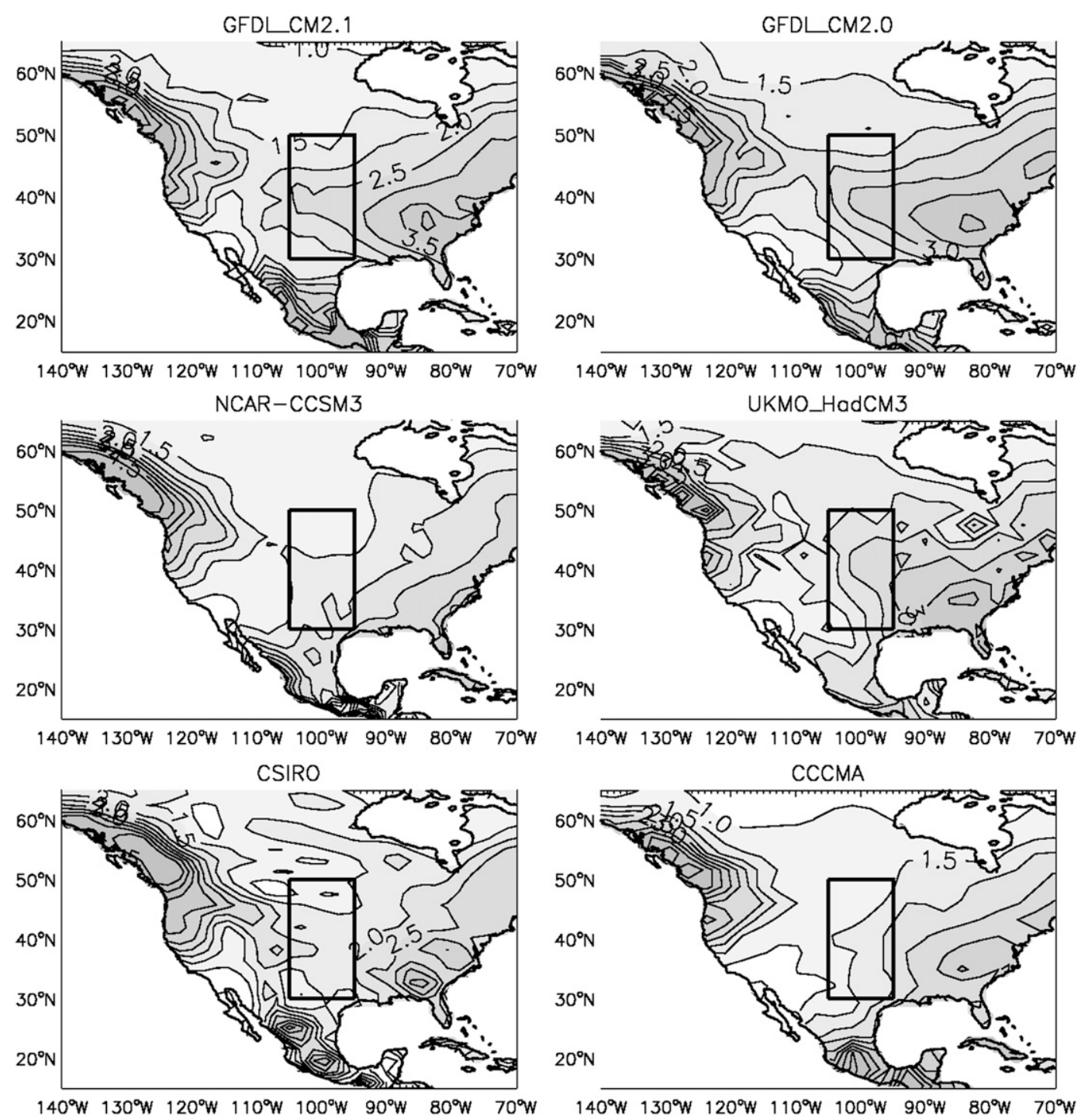

FIG. 2. As in Fig. 1, but for the six climate models. Annual averages are based upon the total duration of the PICNTRL simulations.

unrealistic. To validate the model precipitation fields we use the precipitation climatology developed at the Global Precipitation Climatology Center (GPCC; see online at http://gpcc.dwd.de). This dataset uses a high number of rain gauge-based precipitation data to produce a monthly climatology interpolated on a $1^{\circ} \times 1^{\circ}$ grid from 1901 to 2007. SST data from the extended reconstructed SST dataset (ERSST) developed at the National Atmospheric and Oceanic Administration (NOAA; Smith et al. 2008), also available as monthly means on a $1^{\circ} \times 1^{\circ}$ grid from 1854 to the present, have been used to provide an observational term of comparison for the precipitationSST relationship as well as for the patterns of the leading modes of SST variability. Since SST observations in the 1800 s are sparse, and the quality of the reconstructed data may be somewhat questionable, only values after 1900 have been used.

\section{Mean precipitation over North America}

The annual mean precipitation from the GPCC dataset (Fig. 1) is characterized by precipitation maxima along the coastal regions of the American Northwest, and in the area close to the Gulf of Mexico, with decreasing values in the central and southwestern areas of the United States. Following Schubert et al. (2004a), we will focus on the region of the Great Plains $\left(30^{\circ}-50^{\circ} \mathrm{N}, 95^{\circ}-105^{\circ} \mathrm{W}\right)$, as shown by the box in Fig. 1. The GP lie in the region of strong zonal gradients of mean precipitation and can be affected by variations in the moisture supply from the Gulf of Mexico. 


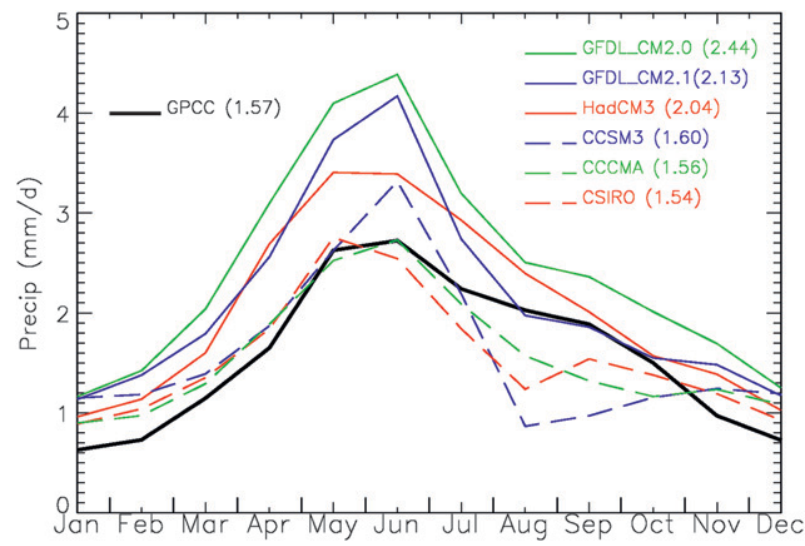

FIG. 3. Seasonal cycle of precipitation $\left(\mathrm{mm} \mathrm{day}^{-1}\right)$ in the GP region from the GPCC dataset (black line) and the six climate models.

The mean precipitation in the models, computed as the annual average over the total duration of the PICNTRL simulations (Fig. 2) also shows maxima in both the Northwest and Southeast of the United States, but the spatial extension, amplitude, and exact locations of the maxima are not represented correctly. For example, the precipitation maximum near the Gulf of Mexico is displaced north of Florida in all the models, and the precipitation gradients across the GP are not zonal and tend to be more diffuse in the models compared to observations. Overall, the models tend to slightly underestimate precipitation in the southeastern United States and overestimate precipitation in the central and southwestern United States. These results are consistent with the findings of McAfee and Russell (2010, unpublished manuscript), who have examined wind speeds and cold season (November-April) precipitation in the twentieth-century simulations of 18 models from the IPCC AR4 archive. They found that the model's attenuation of orography over the Rocky Mountains is responsible for increasing the zonality of the atmospheric circulation, leading to faster wind speeds near $30^{\circ} \mathrm{N}$ and wet biases over western North America, as well as to a general distortion of the precipitation pattern.

The seasonal evolution of precipitation is also very important. Over the GP the observed precipitation evolution (black line in Fig. 3 ) achieves maximum values of approximately $2.5 \mathrm{~mm}$ day $^{-1}$ in May-June, with a slow decrease during the late summer/fall months to minimum winter values of approximately $0.6 \mathrm{~mm}$ day $^{-1}$. The values in Fig. 3 are based on the area-averaged precipitation over the Great Plains box in Fig. 1. The models show a qualitatively similar seasonal evolution, with maxima in late spring/summer. Some models [Geophysical Fluid Dynamics Laboratory Climate Model version 2.0 (GFDL
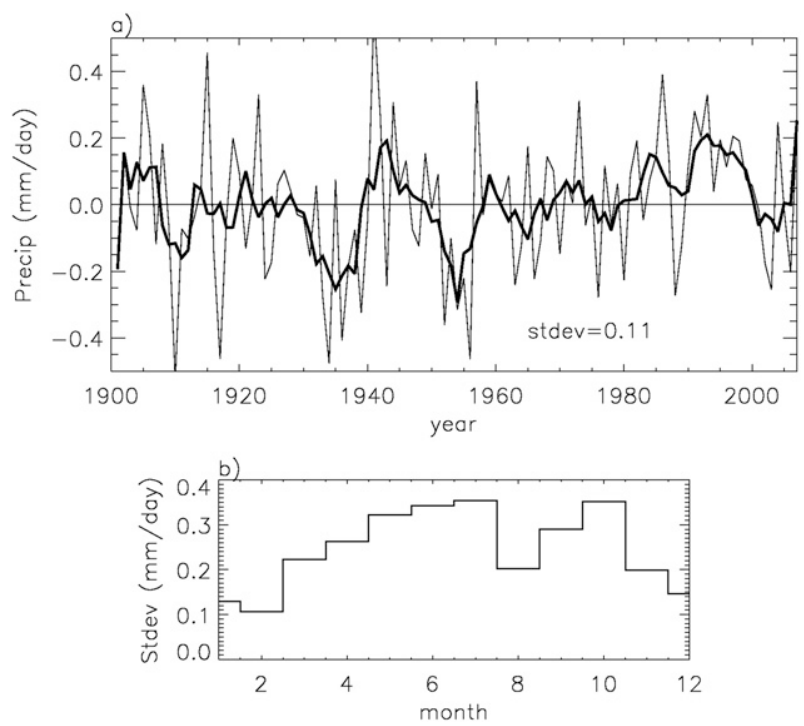

FIG. 4. (a) Evolution of precipitation $\left(\mathrm{mm} \mathrm{day}^{-1}\right)$ over the GP region from the GPCC dataset, including annual values (thin curve) and 5-yr running mean (thick curve). The standard deviation of the 5 -yr running mean time series is $0.11 \mathrm{~mm} \mathrm{day}^{-1}$. (b) Monthly standard deviation of the 5 -yr running mean precipitation $\left(\mathrm{mm} \mathrm{day}^{-1}\right)$.

CM2.0), GFDL CM2.1, and the third climate configuration of the Met Office Unified Model (UKMO HadCM3)] have overall higher values, as indicated by the annual averages (numbers in parenthesis), while other models [CCSM3, Commonwealth Scientific and Industrial Research Organisation (CSIRO), Canadian Centre for Climate Modelling and Analysis (CCCMA)] have annual averages of precipitation very close to the observed, but the seasonal evolution decreases too rapidly in late summer/early fall. The GFDL CM2.1 and the GFDL CM2.0 have a seasonal evolution of precipitation throughout the year similar to that from GPCC but with much higher values, especially at the peak (approximately $4.3 \mathrm{~mm}$ day $^{-1}$ for GFDL CM2.1, and $4.1 \mathrm{~mm} \mathrm{day}^{-1}$ for GFDL CM2.0). The amplitude of the seasonal cycle in the models GP region is mainly related to the position of the GP area, as identified by the boxes in Fig. 2, relative to the spatial pattern of the models wet biases as well as the magnitude of the biases. As seen in Fig. 2, the GP region significantly overlaps areas of greater than observed precipitation in GFDL CM2.1, GFDL CM2.0, and UKMO HadCM3. Similar biases are found in the seasonal evolution of precipitation in the core region of the North American monsoon (central-northwest Mexico and a small portion of Texas), as diagnosed in the twentieth-century simulations of the IPCC AR4 models by Liang et al. (2008). The representation of interannual monsoon variability, likely associated with larger-scale processes, was more realistic in the models. In spite of the models deficiencies in the representation of GP precipitation, we think that they can be 

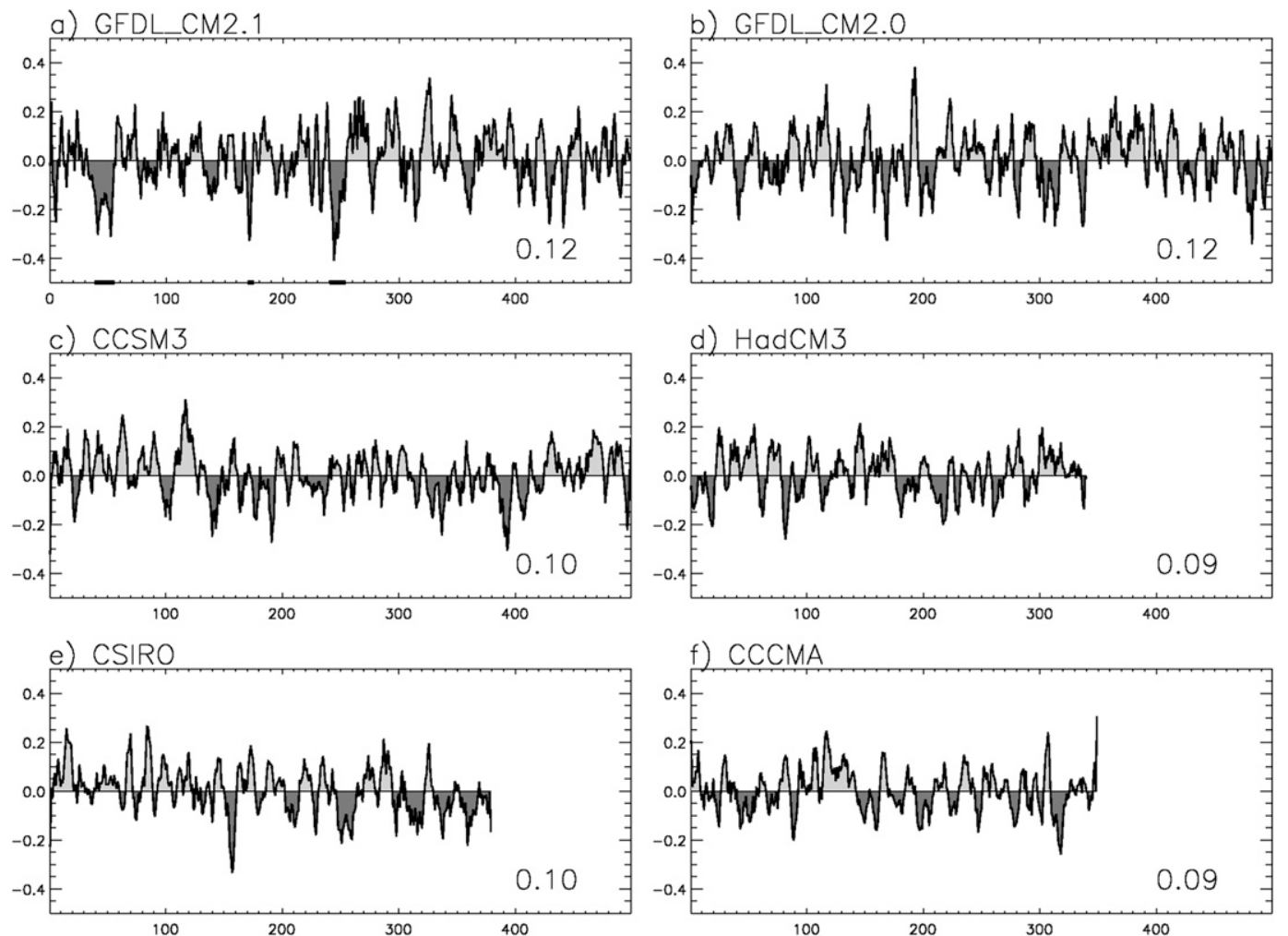

FIG. 5. Low-pass-filtered time series of GP precipitation $\left(\mathrm{mm} \mathrm{day}^{-1}\right)$ for the six climate models over the duration of their PICNTRL simulations. The low-pass filtering has been performed by applying a 5-yr running mean to the annual values. The standard deviations of the time series are shown in the bottom right corner of each panel. The bold segments in (a) indicate the periods considered for composites.

useful for examining the relationship between precipitation and SST.

\section{Low-frequency precipitation evolution in the Great Plains region}

The observed evolution of precipitation over the twentieth century, and beginning of the twenty-first century, as rendered by the GPCC dataset, is shown in Fig. 4a. The thin curve in Fig. 4 is for annual precipitation anomalies, while the thick curve is obtained by applying a 5-yr running mean to the annual values, in order to isolate "decadal" droughts. Multiyear periods of precipitation deficits can be seen near 1910, as well as in the 1930s and 1950s. Low-pass-filtered precipitation anomalies during the 1930s and 1950s droughts are on the order of $0.2 \mathrm{~mm}^{\text {day }}{ }^{-1}$, which is approximately $13 \%$ of the annual mean precipitation (1.57 mm day ${ }^{-1}$, Fig. 3). The standard deviation of the low-pass-filtered time series is $0.11 \mathrm{~mm} \mathrm{day}^{-1}$.

While Fig. 4a provides an annually averaged perspective of the precipitation evolution, it is also important to determine the seasonal dependency of the precipitation anomalies. Figure $4 \mathrm{~b}$ shows the standard deviation of the decadal precipitation anomalies as a function of calendar month. A 5-yr running mean has been applied to the time series for each individual month, prior to computing the standard deviation shown in Fig. 4b. The greatest anomalies are found in summer (June-July), the rainy season, with a second maximum in October. While the high June-July standard deviation is somewhat expected, the high standard deviation in October is more intriguing, and we do not have an explanation for the high precipitation variations in October. The maxima in July and October differ from the August minimum with a high statistical confidence, based on an $F$ test.

The low-pass-filtered (5-yr running mean applied to annually averaged values) evolution of precipitation over the Great Plains region in the six IPCC models (Fig. 5) also shows the occurrence of multiyear periods of precipitation deficit. To compare the model-simulated droughts with the major droughts of the twentieth century, we will use a loose definition of "decadal droughts" as periods with lower-than-average precipitation lasting for more than approximately 5 years in the 5-yr running mean time series. The standard deviation of the time series (shown in the bottom-right corner of each panel) is similar to that 

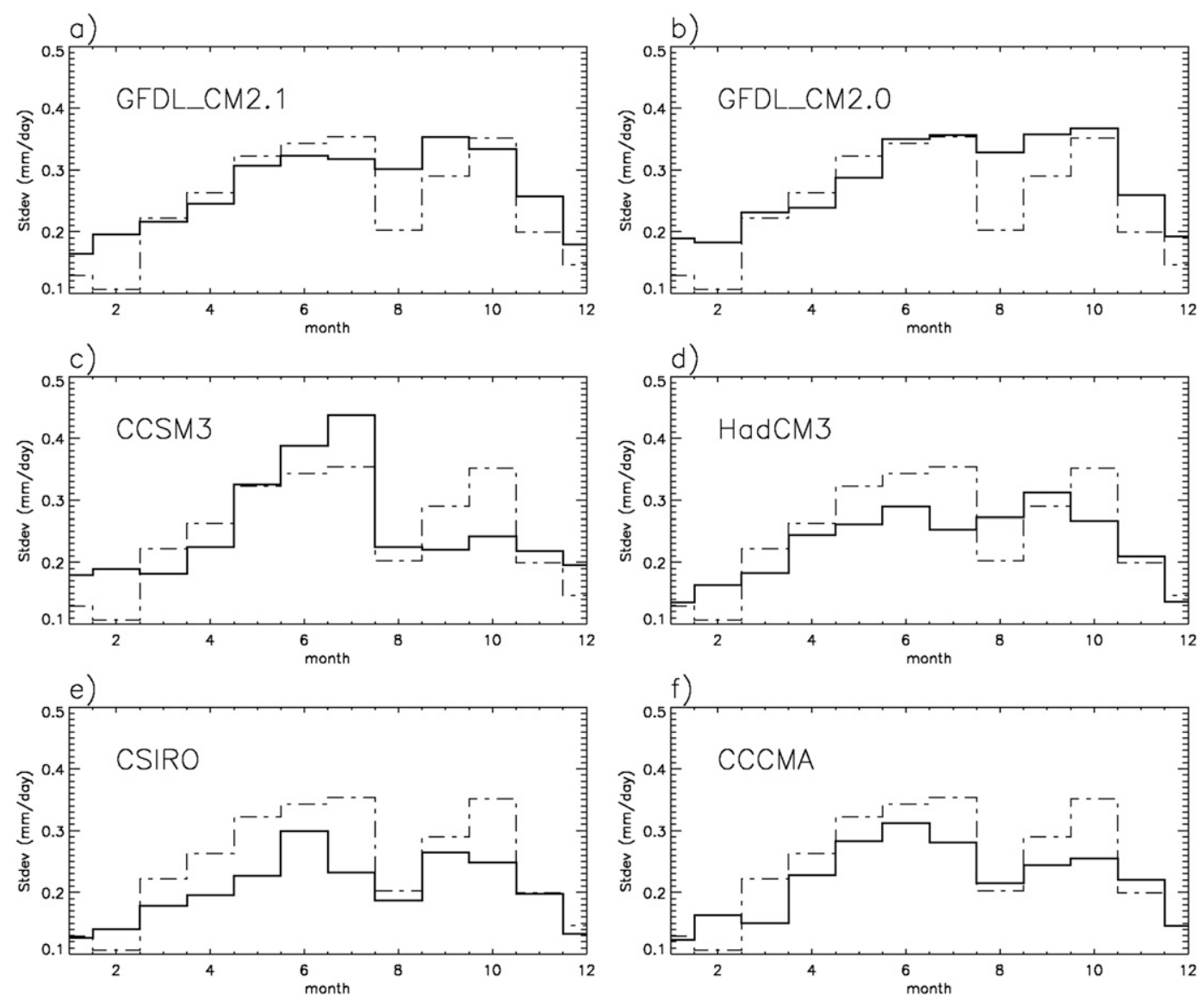

FIG. 6. Standard deviation of 5-yr running mean precipitation $\left(\mathrm{mm} \mathrm{day}^{-1}\right)$ as a function of calendar month for the six climate models. The dotted-dashed line in each panel shows the monthly standard deviation of precipitation for GPCC.

of the observed time series, and the magnitude of some of the negative precipitation anomalies, relative to the mean annual precipitation, is also comparable to that associated with the twentieth-century droughts. For example, for the GFDL CM2.1 low-frequency precipitation anomalies are as high as $0.3 \mathrm{~mm} \mathrm{day}{ }^{-1}$, which is approximately $14 \%$ of the mean annual value $\left(2.13 \mathrm{~mm} \mathrm{day}^{-1}\right.$, Fig. 3$)$, a value comparable to the $13 \%$ obtained for the observational time series. The seasonal distribution of the decadal precipitation anomalies in the models, as described by monthly standard deviations is shown in Fig. 6. Except for CCSM3, the models have two standard deviation maxima, one in the summer and one in the fall, as in the observations, but either the maxima are not as great as in the observations or the late summer decrease in standard deviation is not as pronounced. CCSM3 shows a high maximum in July, but the standard deviations decrease rapidly in late summer and remain low throughout the fall and winter.

To examine whether precipitation anomalies in the GP region are associated with large-scale SST and precipitation changes, as found in AMIP simulations, we start by computing composites of the SST and precipitation conditions during periods of extensive precipitation deficit in the GP. An example from the GFDL CM2.1 is given in Fig. 7, which shows average SST (blue-red shading over the ocean) and precipitation over land (brown-green shading over land) anomalies during years $38-55,170-175$, and 240-255, periods highlighted by the thick lines on the bottom axis of Fig. 5a. In all three periods chosen, there are cold conditions in some areas of the tropical Pacific, as well as in the eastern North and South Pacific, with anomalies of opposite sign in the western midlatitudes. Anomalies in other oceans are less consistent from period to period. For example, the North Atlantic is cold in years $38-55$ but has some warm areas in the other two periods. The average composite (bottom right panel) shows that the high SST anomalies are found in the Pacific. In the tropical Pacific the coldest conditions are located in the western half of the basin, with maximum values of approximately $0.5^{\circ} \mathrm{C}$. The differences in the SST pattern seen in the three 


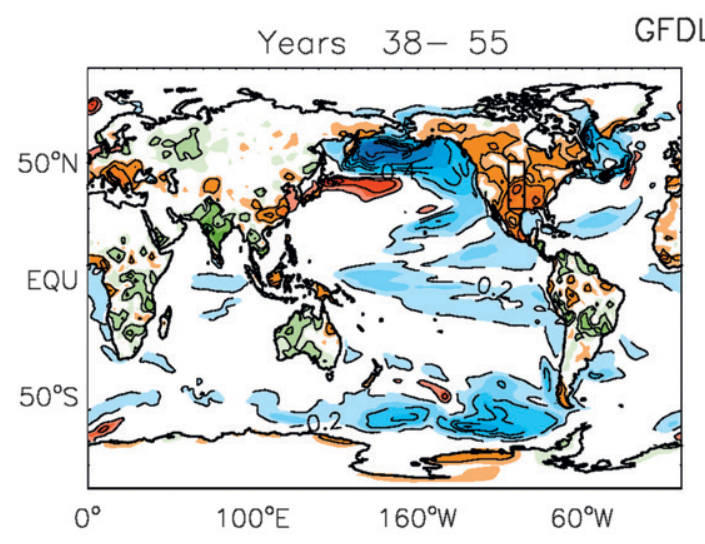

CM21

Years $170-175$
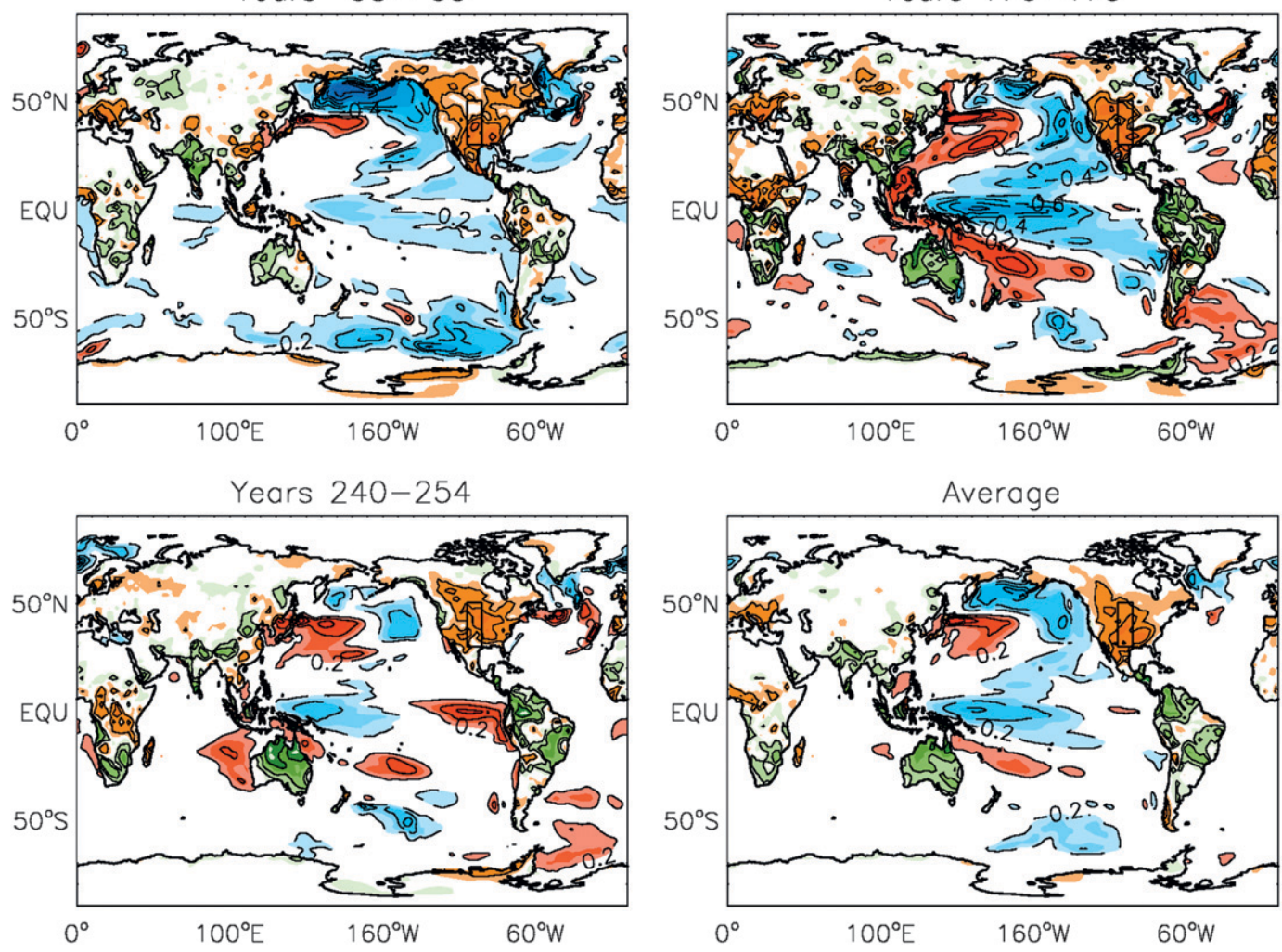

FIG. 7. Composites of SST $\left({ }^{\circ} \mathrm{C}\right.$; red-blue shading) and precipitation ( $\mathrm{mm} \mathrm{day}^{-1}$; orange-green shading) over land for the GFDL CM2.1 model, during years (top left) 38-55, (top right) 170-175, and (bottom left) 240-254. All the periods considered are characterized by lower-than-average 5-yr running mean precipitation in the GP region. (bottom right) The average of the three composites. SST contour interval is $0.2^{\circ} \mathrm{C}$, with values $>0.2^{\circ} \mathrm{C}$ and $<-0.2^{\circ} \mathrm{C}$

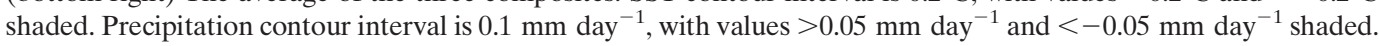

composites are consistent with the differences in the average SST conditions during observed droughts (see Fig. 3 in Seager et al. 2007, showing the SST patterns for the periods 1890-96, 1932-39, and 1948-57, all characterized by lower-than-average precipitation in the central United States).

When the GP are dry, all the composites and their average show that dry conditions also occur over Europe, some parts of Asia, central Africa, and southern South America, while northern South America, southern Africa, India, and Australia are anomalously wet, consistent with paleoclimate evidence (Seager et al. 2007).

Did the precipitation remain below average during the whole duration of the three drought periods considered for the GFDL CM2.1, and are the cold conditions in the western tropical Pacific during all three periods an indication that the SSTs in the western side of the basin play a more important role than those in the eastern side of the basin? Figure 8 shows the evolution of GP precipitation in the GFDL CM2.1 model over the first $100 \mathrm{yr}$ of the PICNTRL simulation and during years
160-260, based on annual values. The low-pass-filtered curve (thick curve, same as in Fig. 5a) is also shown for comparison. Although, on average, the precipitation was below normal during the three composite periods considered in Fig. 7, there were high year-to-year excursions in all three periods. Between years 38 and 55 there were two years when the precipitation was back to average conditions, and between years 240 and 254 there were two years in which the precipitation was above normal. To clarify the relationship between the evolution of precipitation and SST in both sides of the equatorial Pacific we consider two equatorial boxes: a western Pacific box $\left(5^{\circ} \mathrm{S}-5^{\circ} \mathrm{N}, 140^{\circ} \mathrm{E}-180^{\circ}\right)$ and an eastern Pacific box $\left(5^{\circ} \mathrm{S}-5^{\circ} \mathrm{N}, 150^{\circ}-110^{\circ} \mathrm{W}\right)$. The SST evolution in the western box for the two century-long periods considered is shown in Figs. $8 \mathrm{c}$ and $8 \mathrm{~d}$, respectively, while the SST evolution in the eastern box is shown in the lower panels of Fig. 8. In the western equatorial Pacific the SST anomalies tend to be biased toward negative values. Positive anomalies are not warmer than $1^{\circ} \mathrm{C}$, while negative anomalies can be as great as $-2.5^{\circ} \mathrm{C}$. During the periods considered for the 

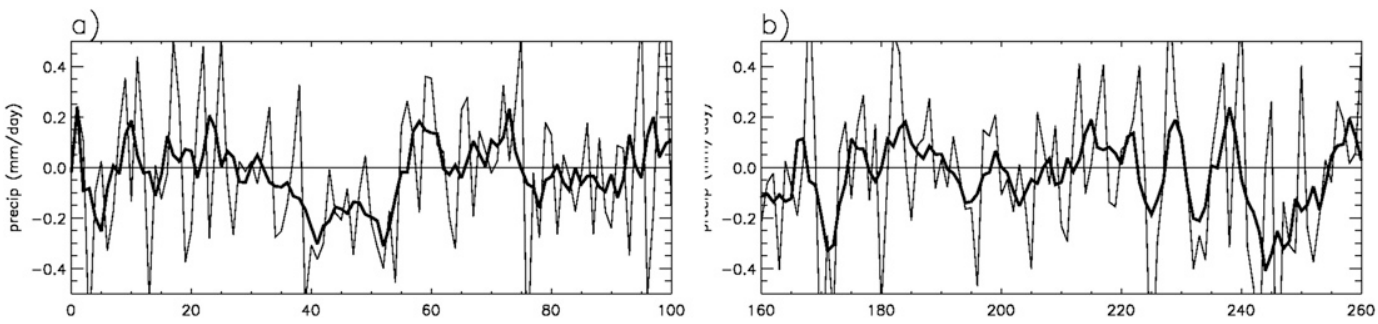

c) West Pacific

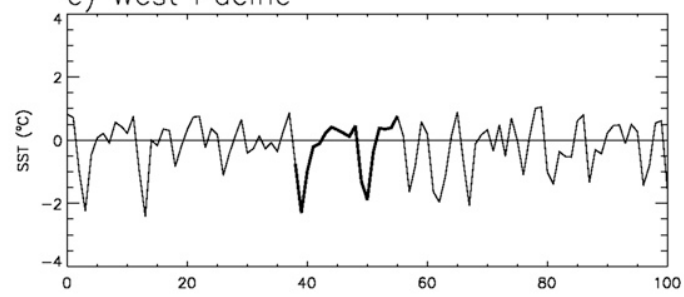

d) West Pacific
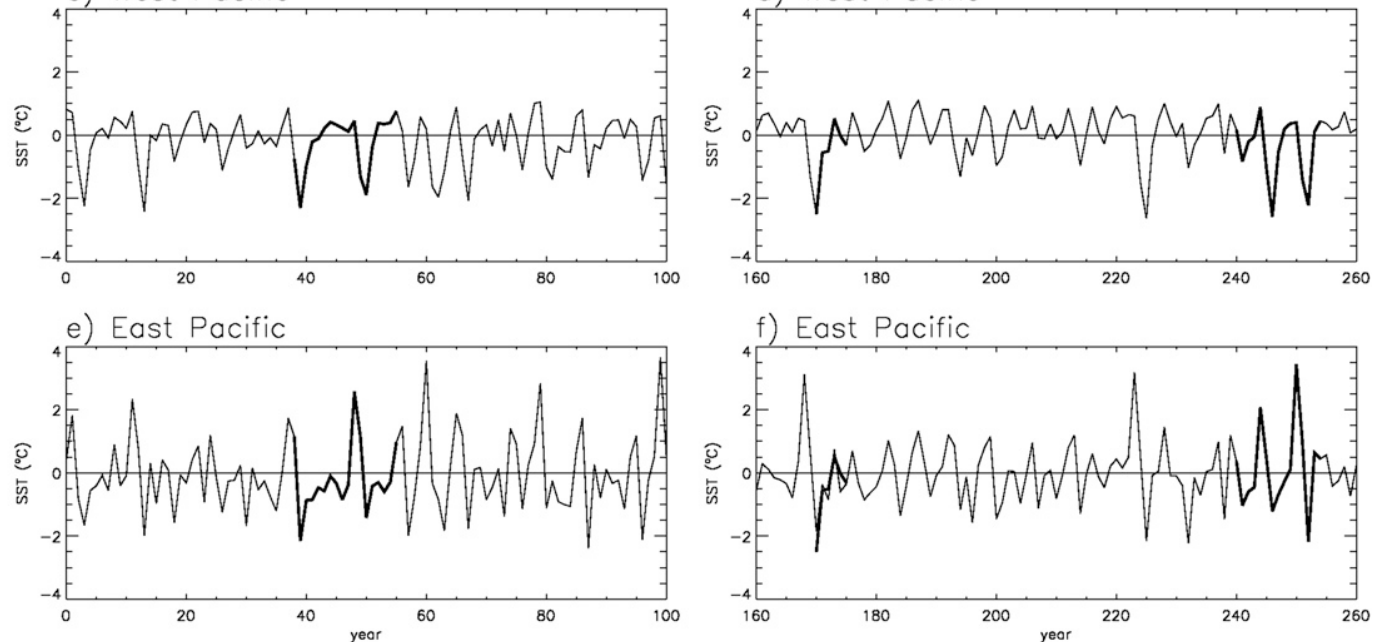

FIG. 8. (a) Time series of precipitation in the GP region during the first $100 \mathrm{yr}$ of the simulation. Thin line indicates the annual values, while the thick line shows the low-pass-filtered curve. (b) As in (a), but for years 160-260. (c) Evolution of SST in the box $5^{\circ} \mathrm{S}-5^{\circ} \mathrm{N}, 140^{\circ} \mathrm{E}-180^{\circ}$, based on annual values for years $1-100$. (d) As in (c), but for years $160-260$. (e) Evolution of SST in the box $5^{\circ} \mathrm{S}-5^{\circ} \mathrm{N}, 150^{\circ}-110^{\circ} \mathrm{W}$, based on annual values over years $1-100$. (f) As in (e), but for years 160-260. The thick line in (c)-(f) highlights the periods considered for the composites. Units for (a) and (b) are mm day ${ }^{-1}$ and for (c)-(f) are ${ }^{\circ} \mathrm{C}$.

composites (highlighted with a thicker line in Figs. 8c-f) the western equatorial Pacific was colder than average. In the eastern equatorial Pacific, on the other hand, SSTs underwent high positive and negative interannual variations, resulting in average conditions, over decadal periods, which are closer to neutral. During years 38-55 and 240-254 the positive anomalies in the eastern Pacific coincide with the return to normal or above-average conditions in GP precipitation (thin line in Figs. $8 \mathrm{a}$ and $8 \mathrm{~b}$ ). Thus, the eastern Pacific appears to be important for the evolution of precipitation over the GP region in this particular model, but its influence seems stronger at interannual time scales. This is most likely due to the greater interannual SST variability rather than to a change in the teleconnections as a function of frequency.

Another approach to examine the relationship between GP precipitation and global SSTs and precipitation is through correlation analysis. We start by considering the correlation between the observed precipitation time series and SST from the NOAA ERSST dataset. All time series have been low-passed filtered by applying the 5-yr running mean. Figure 9 shows the correlation pattern over the global ocean. Strong positive correlations (positive SST anomalies are associated with positive precipitation anomalies in the GP region) are found in a triangular region centered along the equatorial Pacific and extending toward the midlatitudes along the western coast of the Americas. Positive correlations are also found in the South Pacific, South Atlantic, and Indian Ocean, while strong negative correlations are present in the North Atlantic. The number of degrees of freedom, computed following Trenberth (1984), varies geographically from 10 to 20 degrees of freedom in the central and eastern equatorial Pacific. Thus, only correlations greater than approximately 0.45 in the tropical and South Pacific and the North Atlantic are statistically significant at the 95\% level, based on a $t$ test approach.

A similar correlation analysis is performed for the six climate models (Fig. 10). Because of the multicentury duration of the models output, the number of degrees of freedom is greater than for observations, exceeding 80 for the two GFDL models and CCSM3 and 60 for HadCM3, CSIRO, and CCCMA over a large part of the ocean. Correlations greater than approximately 0.2 are 


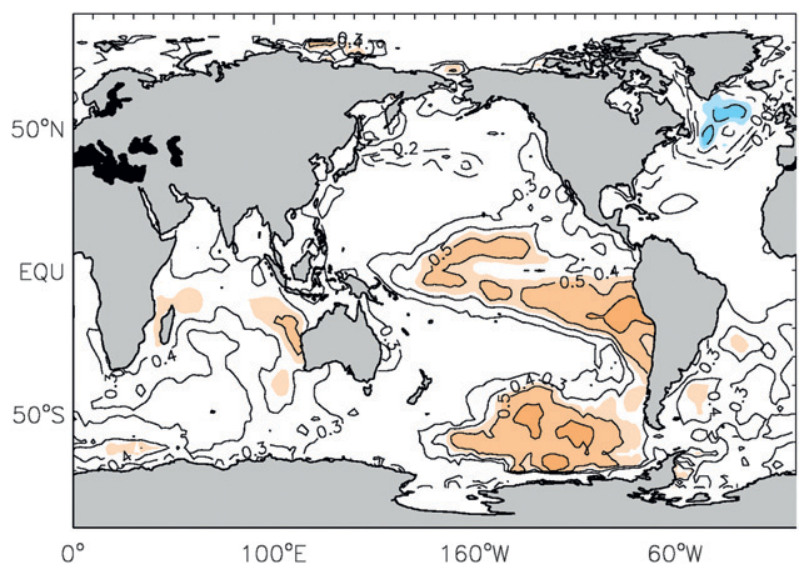

FIG. 9. Correlation between 5-yr running mean GPCC precipitation and 5-yr running mean NOAA ERSST. Contour interval is 0.1 . Values $>0.45$ (orange) and $<-0.45$ (blue) are statistically significant at the $95 \%$ level.

statistically significant at the $95 \%$ level for the first three models, while for HadCM3, CSIRO, and CCCMA statistically significant correlations must be greater than approximately 0.25 . Results from the models confirm the central role of the tropical Pacific, where statistically significant positive correlations are found in all the models. Although the exact locations of maximum correlations vary among models, in all cases the spatial pattern of correlation in the Pacific has a triangular structure similar to that seen in Fig. 9 for observations. GFDL CM2.1, HadCM3, and CSIRO have statistically significant positive correlations in the Indian and tropical Atlantic Oceans. Significant correlations in the South Pacific are only found for GFDL CM2.1 and CSIRO. Except for CCSM3 and GFDL2.0, the correlation patterns in Fig. 10 are similar to the patterns of the leading SST empirical orthogonal functions (EOFs, which are shown in Fig. 15 and discussed in section 5), an indication that midlatitude SST anomalies in those models are correlated with the tropical SST anomalies. Thus, the presence of statistically significant correlations in the extratropics does not necessarily imply that those anomalies directly force GP precipitation. Indeed, as shown in sensitivity studies using AMIP-type simulations where anomalous SSTs were specified only in selected regions (Schubert et al. 2004a; Seager et al. 2005), only tropical SST anomalies were relevant in forcing GP precipitation.

The correlations between low-frequency precipitation in the Great Plains and the global precipitation field are shown in Fig. 11. Values greater than approximately 0.2 are statistically significant at the $95 \%$ level. Although the precipitation patterns are noisier than the SST correlation patterns, the global character of the precipitation changes clearly emerges in Fig. 11, with characteristics similar to those described by Schubert et al. (2004a). Wet conditions in the Great Plains are associated with increased precipitation in the western equatorial Pacific, and along a band extending southeastward from the western tropical Pacific to the tip of South America. Positive precipitation anomalies are found over Europe and/or the Mediterranean area in most models, but they tend to be below the $95 \%$ significance level. Negative correlations (dry conditions) are found over India and Australia, as well as Central America and northern South America. Notice that there are large differences among models in the magnitude of the correlations away from the GP region. In particular, CCSM3 and, to a lesser degree, CCCMA have very weak correlations. In CCSM3, the only statistically significant correlations (greater than 0.2 ) are in the western equatorial Pacific and in a small area offshore of the western coast of southern South America.

The changes in precipitation over the globe forced by SST anomalies can be expected to occur through atmospheric teleconnections. Figure 12 shows the correlation between low-frequency precipitation in the GP and lowfrequency 200-mb geopotential height. The geopotential height anomalies are characterized by a banded structure with a high degree of zonal symmetry, similar to those described in the AMIP studies of Schubert et al. (2004a), and Seager et al. (2005). Wet conditions over the GP region are associated with raised heights in the tropics and in high latitudes but lower heights in the midlatitudes. One exception is CCSM3, where lower heights are also found in the northern high latitudes. The models consistently show localized lows close to the western coast of the United States, displaced westward with respect to the GP region, and in the central North Pacific, which may be associated to increased storminess, as pointed out by Schubert et al. (2004a). Although the general structure is similar in most of the models, the intensity of the correlations vary significantly from model to model, ranging from maximum values of $0.2-0.3$ in the CCSM3 and CCCMA to values as high as 0.6 in the CSIRO model, where positive correlations dominate. The low correlations in the CCSM3 and CCCMA models may be a consequence of a weak atmospheric response to SST anomalies, or they may result from the magnitude and/ or location of the SST anomalies themselves. The weak atmospheric signal in these models may explain the more limited precipitation response seen in Fig. 11.

Which changes in the atmospheric circulation are associated with the changes in geopotential height? The high degree of zonal symmetry in the height field justifies a zonal average perspective. Figure 13 shows correlations between decadal precipitation anomalies in the GP region and temporal anomalies in the zonal-mean 
a) GFDL_CM2.1
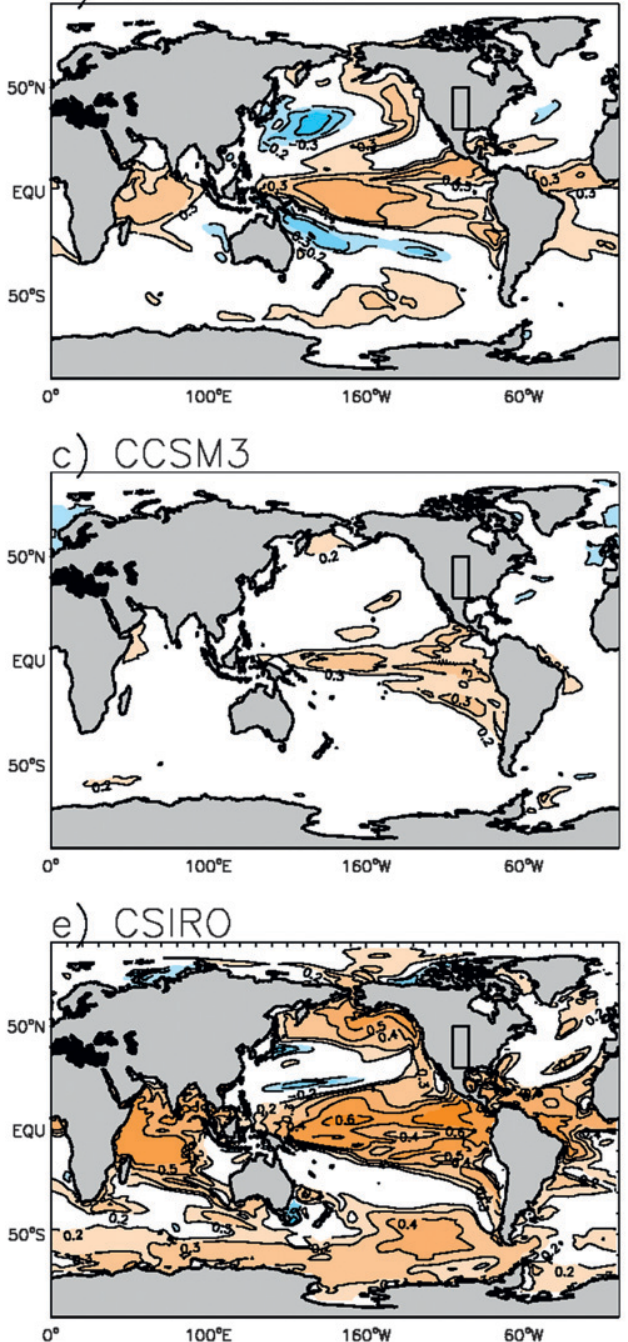

b) GFDL_CM2.0
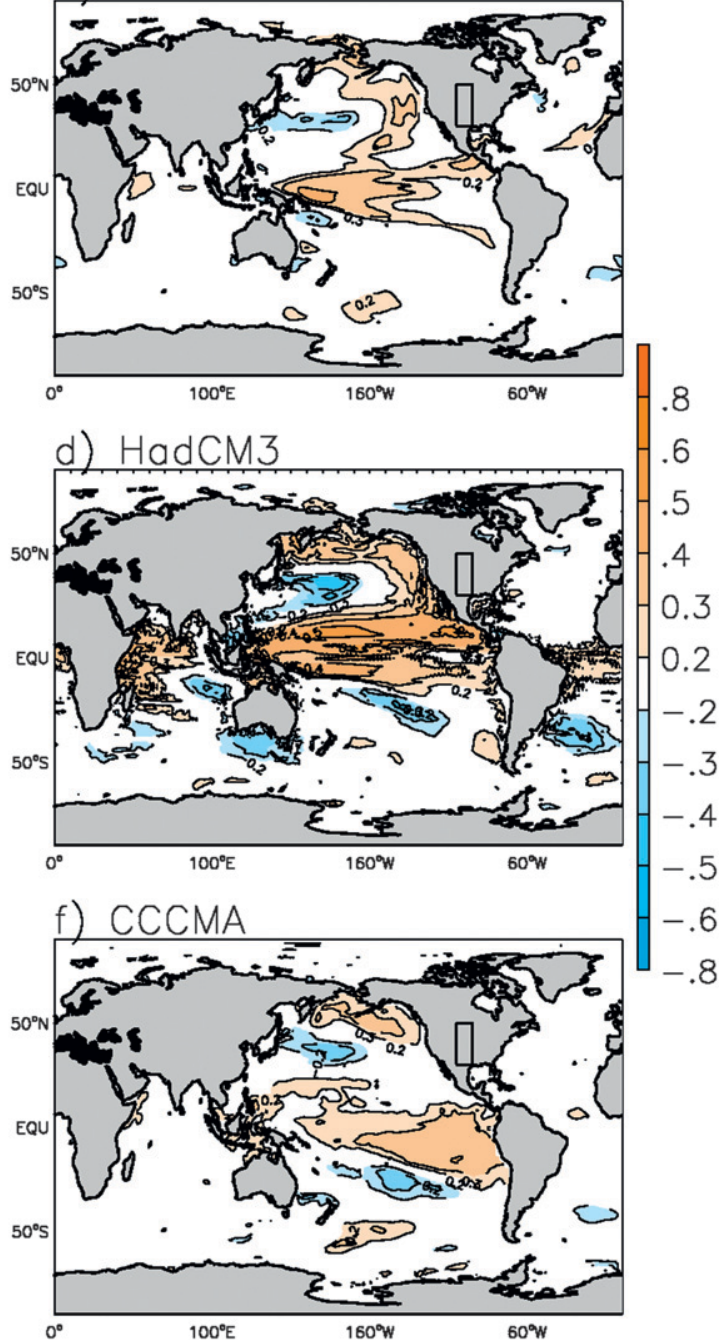

FIG. 10. Correlation between the 5-yr running mean of GP precipitation and 5-yr running mean of SST for the six climate models. Values $>0.2$ (orange) and $<-0.2$ (blue) are statistically significant at the $95 \%$ level for (a) GFDL CM2.1, (b) GFDL CM2.0, and (c) CCSM3. The threshold for statistical significance at the $95 \%$ level is 0.25 for (d) HadCM3, (e) CSIRO, and (f) CCCMA. The Great Plains area is shown by the box over North America.

zonal wind. As for all other fields, anomalies have been computed by subtracting the long-term mean from the annually averaged values prior to applying the 5-yr running mean. The correlations are superimposed upon the mean zonally averaged positive wind velocities, showing the mean position of the midlatitude jets. Correlations greater than approximately 0.2 are statistically significant at the $95 \%$ level. With the exception of the CCSM3, all the models show negative correlations on the poleward flanks of the jets and positive correlations on the equatorward sides of the jets, indicative of an equatorward displacement of the midlatitude jets during periods of greater-than-average GP precipitation, which, in turn, tends to be concurrent with warm conditions in the tropical Pacific. Correlations are particularly high in the GFDL CM2.1, HadCM3, and CSIRO models. GFDL CM2.1, HadCM3, and CCCMA show slightly stronger correlations in the Northern Hemisphere. The changes in atmospheric circulations implied by the correlation patterns in Fig. 13 are in agreement with the results of $\mathrm{Lu}$ et al. (2008, their Fig. 2c), who examined the changes in the zonal mean atmospheric circulation due to El Niño versus global warming in the A2 (high forcing) climate change scenario simulation of the twenty-first century performed with the GFDL CM2.1 model. The changes in the zonal mean atmospheric circulation associated with natural interannual variability show a contraction (expansion) of the Hadley cell during El Niño (La Niña) 

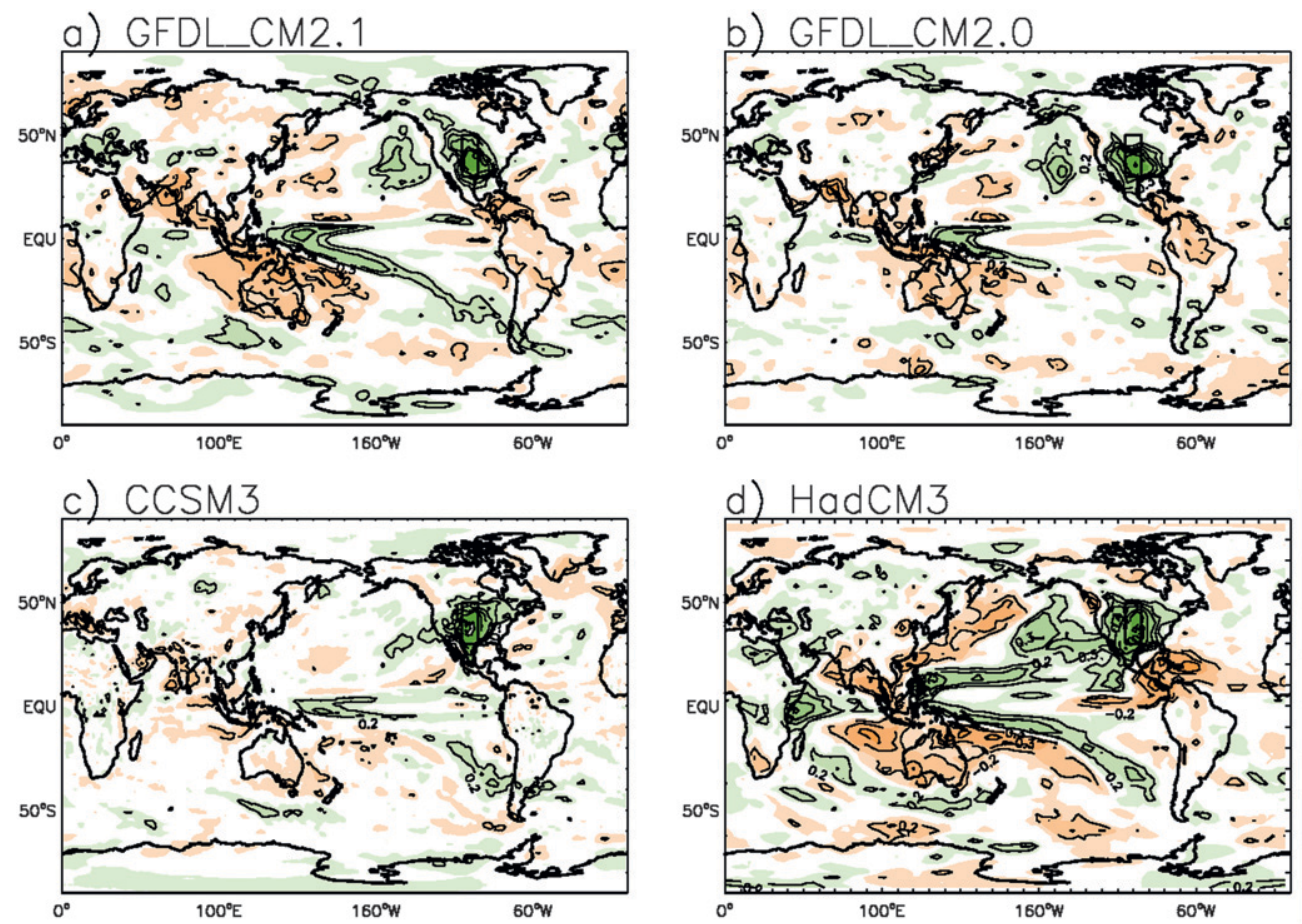

\section{.8}
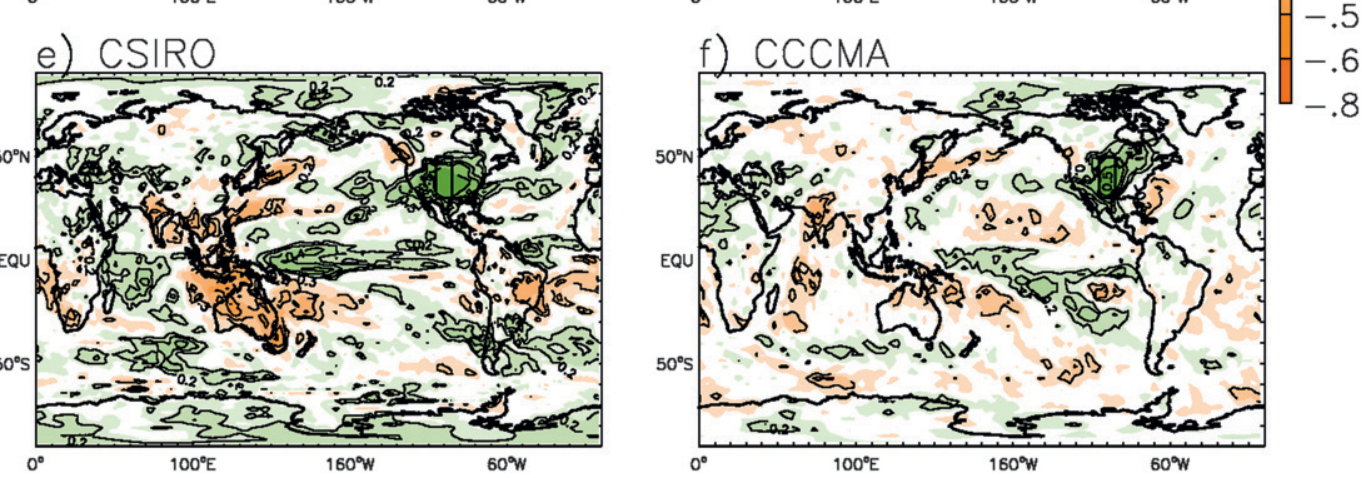

FIG. 11. Correlations between 5-yr running mean GP precipitation and 5-yr running mean global precipitation for the six climate models. Values $>0.1$ (green) represent greater-than-average precipitation and $<-0.1$ (brown) represent lower-than-average precipitation. Values $>0.2$ and $<-0.2$ are contoured and are statistically significant at the $95 \%$ level. Contour interval is 0.1 .

events similar to those seen in Fig. 13. Global warming, on the other hand, results in weakening and poleward expansion of the Hadley cell in spite of the tropical warming.

\section{Relationship between Pacific SST anomalies and modes of SST variability}

The pattern of correlations between GP precipitation and SST in the tropical Pacific is reminiscent of the structure of the IPO (Power et al. 1999), as also discussed in previous studies (Schubert et al. 2004a; Meehl and Hu 2006). To elucidate the connection between low-frequency precipitation variations in the GP region and the leading mode of low-frequency SST variations, we perform an
EOF analysis of the 5-yr running mean SST field. We limit the analysis to the Pacific basin, which is the one that more consistently shows correlations with the GP precipitation in all the models. Figure 14a shows the leading SST EOF for the NOAA ERSST dataset, based on covariance. The pattern of the mode, which explains $30 \%$ of the low-frequency SST variance, is similar to the well-known structure of the IPO (Power et al. 1999), and PDO in the Northern Hemisphere (Mantua et al. 1997). The corresponding principal component (PC; Fig. 14b) has a correlation of 0.56 with the low-pass-filtered GP precipitation time series, which is statistically significant at the $95 \%$ level and marginally significant at the $99 \%$ level. Fig. 14b shows, however, that large precipitation 

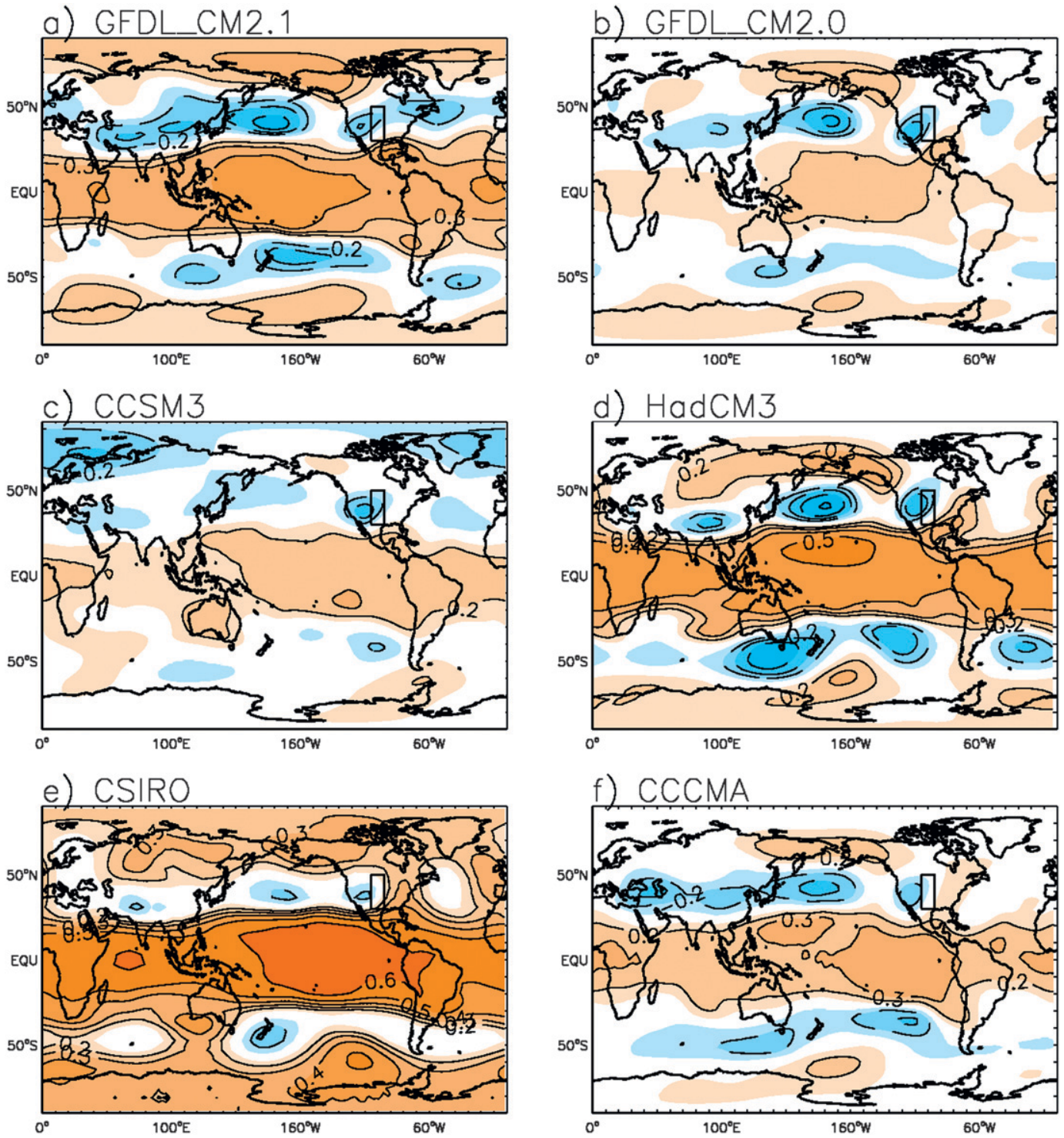

FIG. 12. Correlations between the 5-yr running mean GP precipitation and 5-yr running mean 200-mb geopotential height for the six climate models. Values $>0.1$ (orange) represent positive height anomalies and $<-0.1$ (blue) represent negative height anomalies. Values $>0.2$ and $<-0.2$ are contoured and are statistically significant at the $95 \%$ level. Contour interval is 0.1 .

anomalies, like the Dust Bowl in the 1930s, are not associated with large SST PC1 anomalies, as SSTs were only weakly negative during the Dust Bowl period, as also shown by the averaged SSTs during the 1930s (Schubert et al. 2004b). We note that the observed evolution of SST could be influenced by global warming, unlike the SST fields from the models PICNTRL simulations. No significant trend can be detected in the evolution of the PC in Fig. 14b, indicating that the EOF is primarily associated with natural variability.

The leading EOFs for the six climate models (Fig. 15) exhibit differences in their spatial patterns. While GFDL
CM2.1, HadCM3, CSIRO, and, to a lesser degree, CCCMA, have spatial patterns for their leading decadal SST EOF qualitatively similar to the IPO pattern, in GFDL CM2.0 and CCSM3 the tropical loading is much weaker than in the other models and in the observations. In those models the main centers of actions are in the North Pacific, with a spatial pattern similar to that described by Kwon and Deser (2007) for the National Center for Atmospheric Research (NCAR) Community Climate Model version 2 (CCSM2), an earlier version of the NCAR climate model. Kwon and Deser (2007) have shown that the leading mode of winter SST anomalies in 

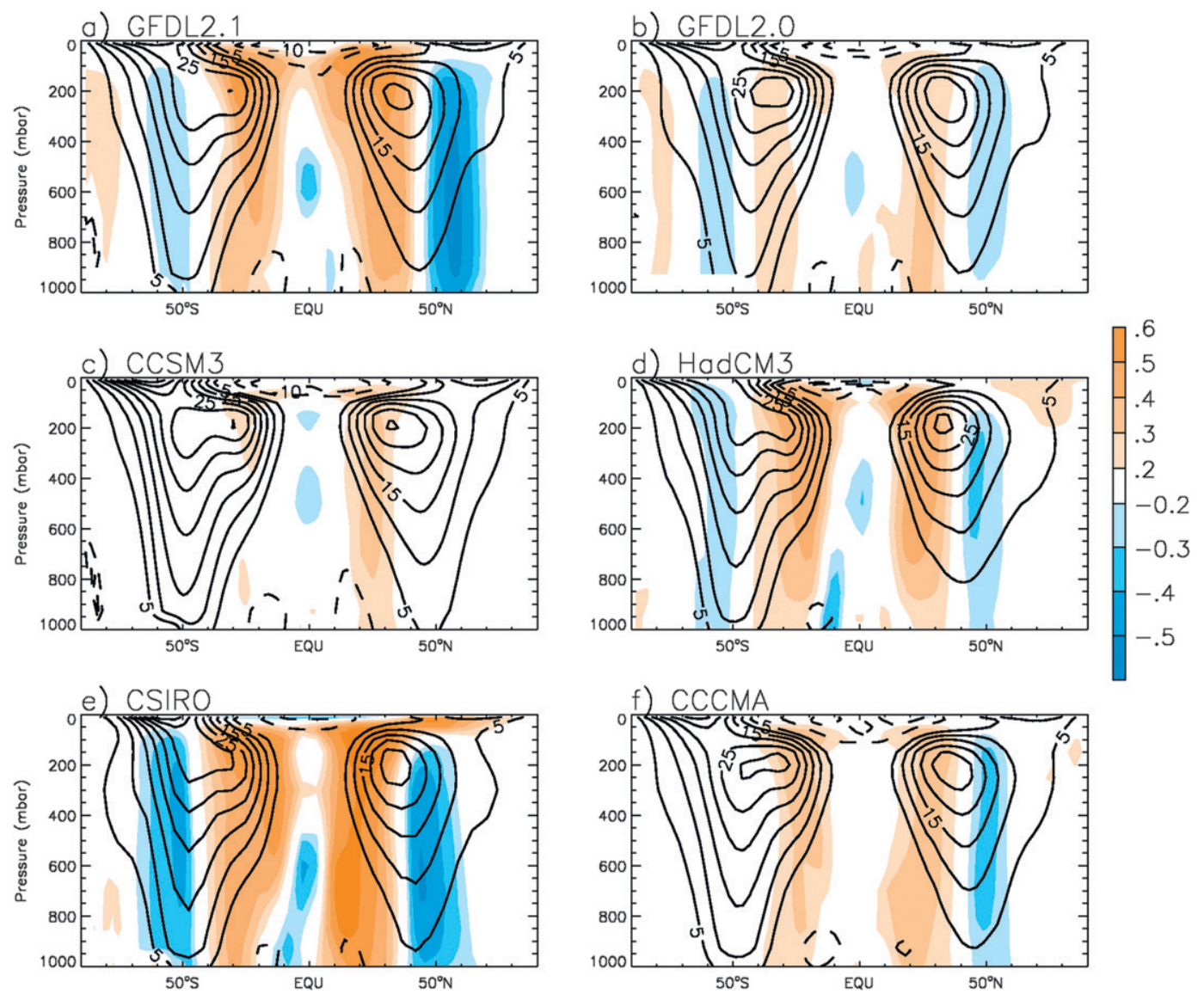

FIG. 13. Correlations between the 5-yr running mean GP precipitation and 5-yr running mean zonal-mean zonal wind (shading) for the six climate models superimposed upon the time-averaged zonal-mean zonal wind (contours; contour interval $5 \mathrm{~m} \mathrm{~s}^{-1}$ ). Positive values are shaded orange, while negative values are shaded blue. Correlations $>0.2$ and $<-0.2$ are statistically significant at the $95 \%$ level. The negative correlations at the poleward flanks of the mean jet and the positive correlations at the equatorward flanks of the jets are an indication of an equatorward displacement of the jets in both hemispheres during periods of greater-than-average precipitation in the GP.

the North Pacific has a pattern similar to the PDO and is characterized by significant spectral peaks in the decadal and interdecadal range. The western center of action is located along the Kuroshio Extension and originates from wind-forced meridional excursions of the Kuroshio Extension. The SST anomalies force, in turn, an atmospheric wind response, so that this mode of variability can be considered a coupled ocean-atmosphere mode. It is likely that the leading EOFs for CCSM3 and GFDL CM2.0 originate from a similar coupled dynamics. The lack of connection of the PDO with the tropics in CCSM3 was also noted by Alexander et al. (2006).

The percentage of explained variance ranges from $20 \%$ in the CSIRO model to $29 \%$ in the GFDL CM2.1 model, in relatively good agreement, for most models, with what was found for the observed SST. The evolution of the corresponding PCs is compared in Fig. 16 with the evolution of GP precipitation in all the models.
Correlation coefficients between the time series, as well as the correlations corresponding to the $95 \%$ significance level, are shown in each panel. Apart from GFDL CM2.0, and CCSM3, whose correlations between GP precipitation and $\mathrm{PC1}$ are only marginally significant, all the other models have statistically significant correlations between the leading SST mode in the Pacific and precipitation in the GP region. The agreement between the two time series is particularly evident, by visual inspection as well as correlation coefficient, for HadCM3 and CSIRO, where the evolution of precipitation seems to track that of SST very closely. The low correlation coefficients for CCSM3 and GFDL2.0 may be a result of their very weak tropical loading. In fact, at least for CCSM3, the only significant correlations between GP precipitation and SST are found in the tropical Pacific (Fig. 10). Also, as demonstrated by other studies (Schubert et al. 2004a; Seager et al. 2005), tropical SST anomalies are the 

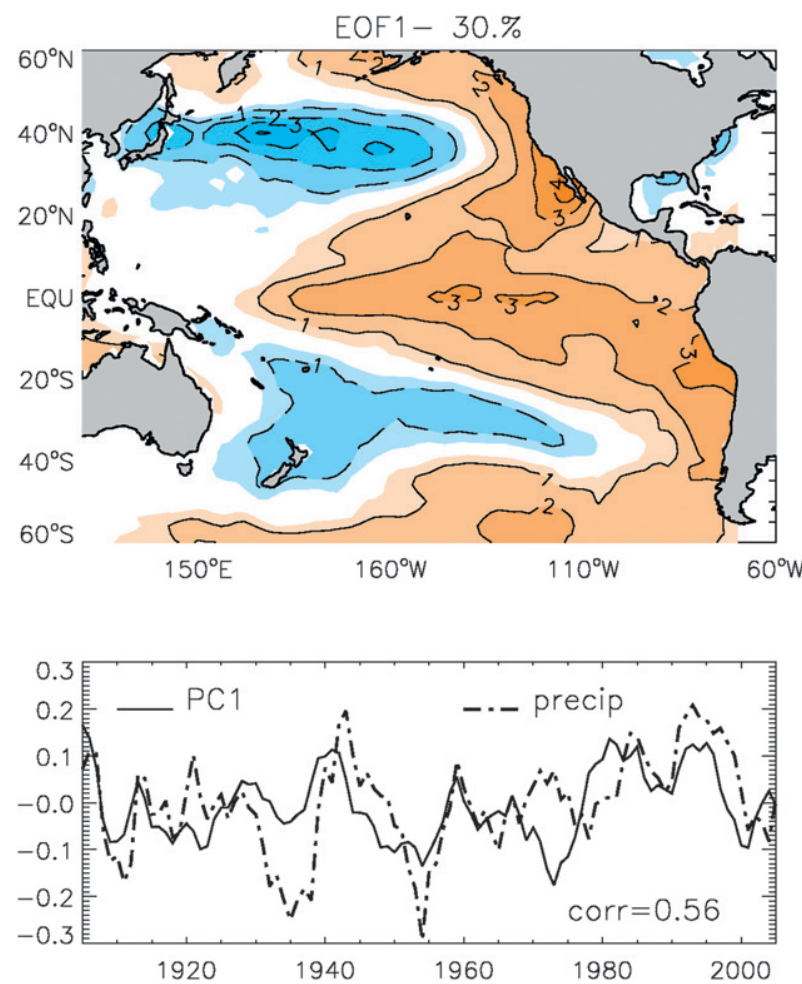

FIG. 14. (top) The leading EOF of 5-yr running mean SST $\left({ }^{\circ} \mathrm{C}\right)$ from the NOAA ERSST dataset. Contour interval is $1^{\circ} \mathrm{C}$. Values $>0.5^{\circ} \mathrm{C}$ are shaded orange, and values $<0.5^{\circ} \mathrm{C}$ are shaded blue. The EOF accounts for $30 \%$ of the low-frequency SST variance. (bottom) The comparison between the PC of the leading SST EOF (solid line) and the 5-yr running mean precipitation from GPCC (dot-dash line). Correlation coefficient between the two time series is 0.56 , statistically significant at the $95 \%$ level

primary players in forcing U.S. precipitation; however, while the second SST EOF for CCSM3 (not shown) has a stronger tropical loading, the correlation coefficient between PC2 and GP precipitation remains only marginally significant. The strongest correlations in Fig. 10 for CCSM3 are approximately 0.3, implying that at the most only approximately $9 \%$ of the GP precipitation variations can be related to remote SST forcing. Thus, in this model low-frequency GP precipitation variations may be more locally driven. Given the low correlations between GP precipitation and atmospheric fields in CCSM3 at the global scale (Figs. 12c and 13c), the primary cause of the weak SST influence on precipitation in this model may be associated with weak atmospheric teleconnections at decadal time scales, a factor that may limit the model predictive skills.

\section{Conclusions}

In this study we have examined the relationship between low-frequency precipitation in the Great Plains region of North America and sea surface temperature (SST) in six of the IPCC AR4 climate models. This study builds upon, and extends to a coupled model context, previous studies performed with atmospheric-only models forced by observed SSTs. We have focused upon preindustrial control simulations, whose multicentury duration allows us to examine the influence of low-frequency SST variations due to natural variability on U.S. precipitation with a high statistical confidence.

In spite of their coarse horizontal resolution, the IPCC climate models reproduce the general features of the spatial pattern of observed mean precipitation over North America, including maxima in the American Northwest and Southeast, with lower values in the central United States. The strong zonal gradients found in observations in the central United States, however, are not as pronounced in the models, and the location of maximum precipitation in the Southeast is displaced with respect to the observed in most models. In the Great Plains region, the rainy season occurs in early summer, with precipitation slowly decreasing toward the minimum winter values. All the models analyzed capture the early summer maximum, but in some of them the maximum as well as the annual average values are too high. In other models, the summer values have approximately the correct amplitude, but the level of precipitation decreases too rapidly than observed in late summer and fall.

The evolution of low-pass-filtered precipitation (using a 5-yr running mean) exhibits multiyear periods of lowerthan-average precipitation of amplitude comparable to that observed during the nineteenth and early twentieth century. Correlation analysis shows that long periods of anomalous precipitation in the Great Plains area are part of a global pattern of anomalous precipitation conditions. In particular, dry conditions in the Great Plains are concurrent with dry conditions over some parts of Europe and southern South America and wet conditions over northern South America, India, and Australia, in agreement with previous studies.

The large-scale pattern of precipitation anomalies is consistent with the large-scale pattern of atmospheric circulation anomalies. Wet conditions in the Great Plains are associated with raised geopotential heights in the tropics and high latitudes in most models and lower heights in the midlatitudes, with a structure characterized by a high degree of zonal symmetry. When the Great Plains are wet, the midlatitude jets tend to be displaced equatorward. These changes in atmospheric circulation are consistent with those accompanying a warm tropical Pacific, as during El Niño events (Seager et al. 2005; Lu et al. 2008).

Correlation analysis between Great Plains low-frequency precipitation and low-frequency SST anomalies indeed 

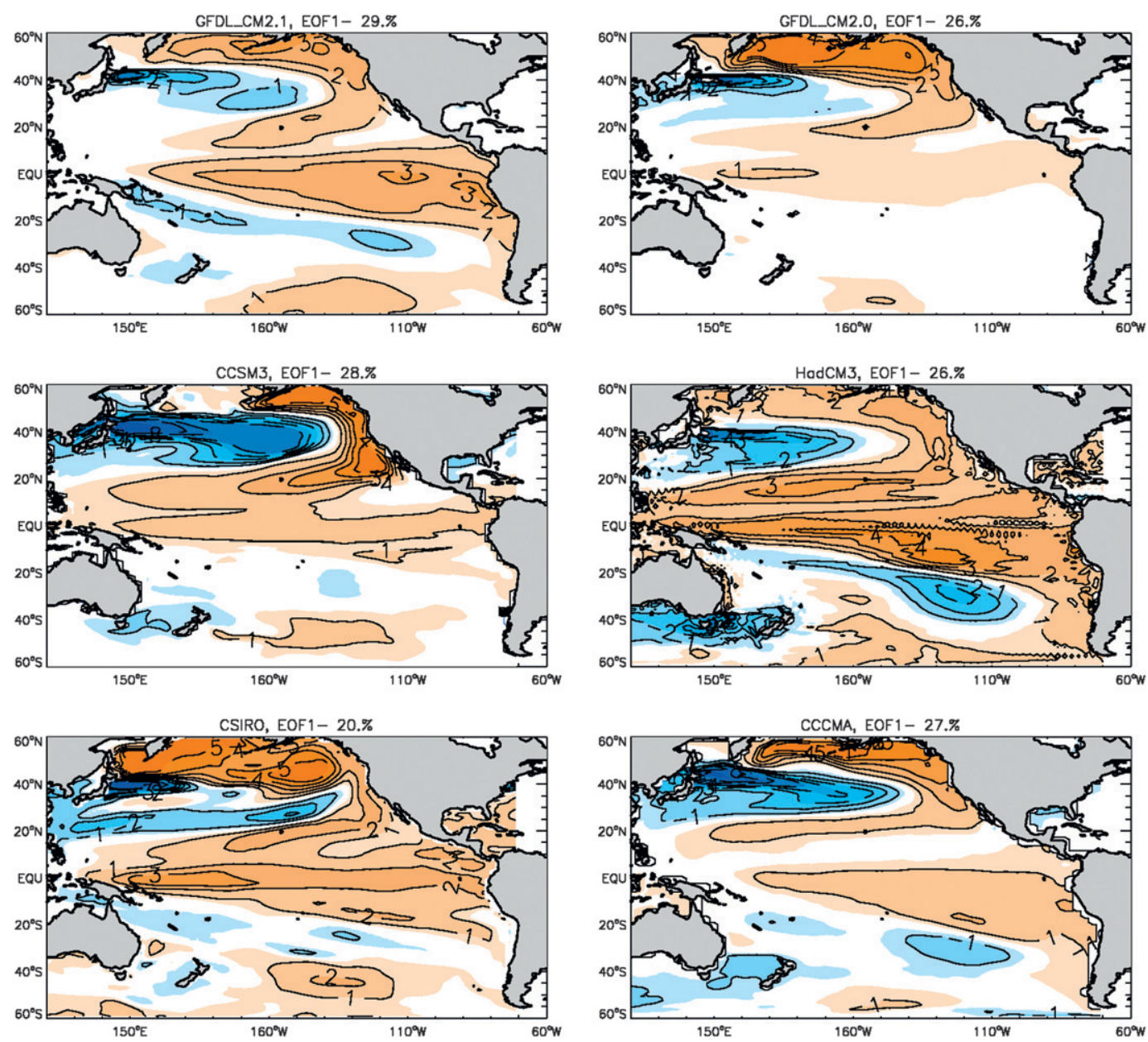

FIG. 15. Leading EOF for the six climate models. Contour interval is $1^{\circ} \mathrm{C}$. Values $>0.5^{\circ} \mathrm{C}$ are shaded orange, and values $<-0.5^{\circ} \mathrm{C}$ are shaded blue. The fraction of variance explained is $29 \%$ for GFDL CM2.1, 26\% for GFDL CM2.0, 28\% for CCSM3, 26\% for HadCM3, 20\% for CSIRO, and 27\% for CCCMA.

shows statistically significant correlations between precipitation and SST in the tropical Pacific. The pattern of correlation has a triangular shape with positive values extending toward the midlatitudes along the western coast of the Americas. In some models negative correlations are found in the central-western midlatitudes of the Pacific, and statistically significant positive correlations are found, in some cases, in the tropical Atlantic and Indian Oceans. The tropical Pacific, however, is the only area that consistently emerges, among the models analyzed, with a statistically significant correlation with Great Plains precipitation.

The spatial pattern of correlation between the observed Great Plains precipitation and SST is somewhat similar to the leading mode of Pacific SST variability at decadal time scales, named the interdecadal Pacific oscillation by Power et al. (1999). The associated principal component tracks relatively well the low-frequency evolution of precipitation over the Great Plains region. A similar correspondence is found for most of the models, but in some cases the correlation between principal component and precipitation is very marginally significant. In these models, the leading SST EOF has a weak loading in the tropical Pacific, with the major centers of action located in the North Pacific, further supporting the evidence that the tropical Pacific is a key area for driving atmospheric circulation and precipitation changes.

Although statistically significant, the correlations between Great Plains precipitation and tropical Pacific SSTs from the multicentury time series of the climate models never exceed $0.4-0.5$. This means that no more than approximately $16 \%-25 \%$ of the Great Plains precipitation variability can be accounted for by SST variations. Internal atmospheric variability and local feedbacks may be responsible for variations in precipitation not directly linked to SST variations. Schubert et al. (2004a) have also 
a) GFDL_CM2.1

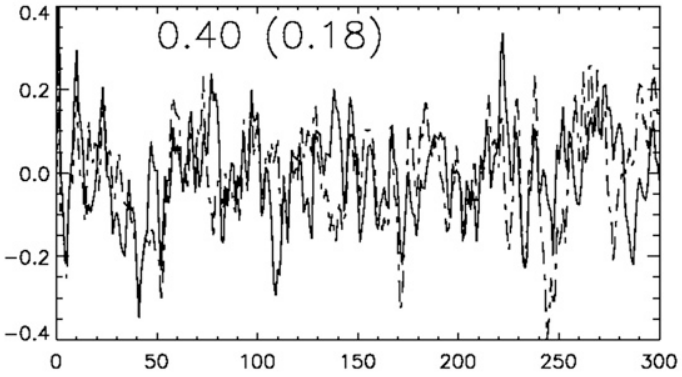

c) $\operatorname{CCSM} 3$

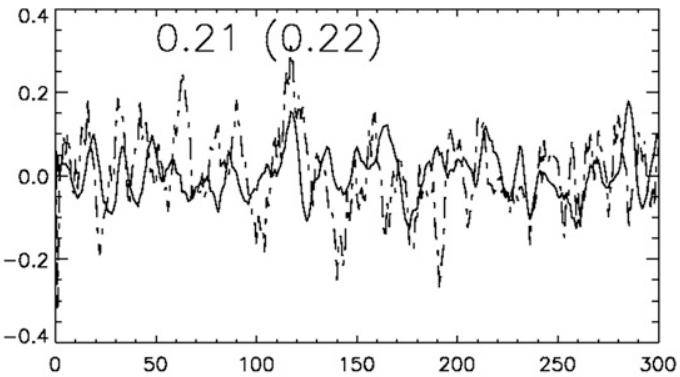

e) CSIRO

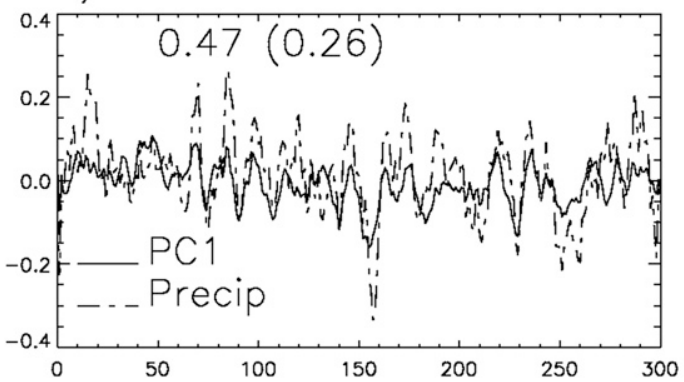

b) GFDL_CM2.0

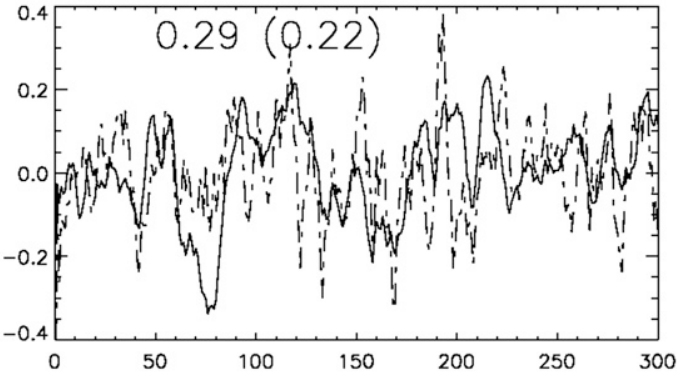

d) $\operatorname{HadCM} 3$

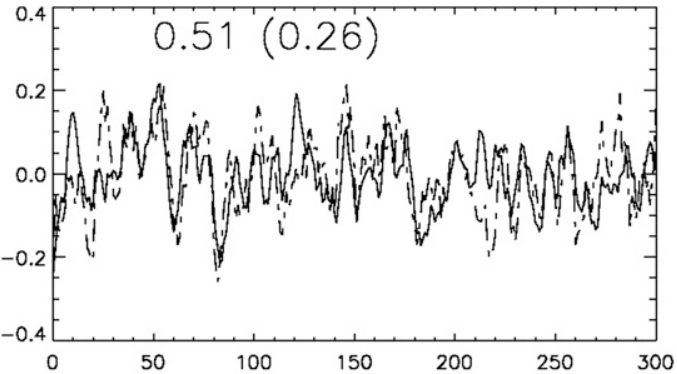

f) CCCMA

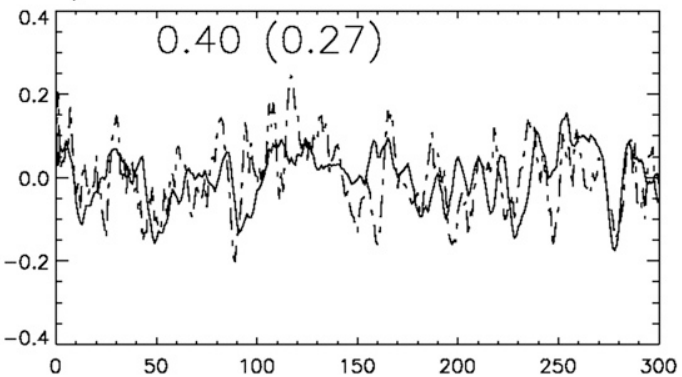

FIG. 16. The evolution of the PC of the leading decadal SST mode in the Pacific Ocean (solid line) for the six climate models is compared with the decadal evolution of GP precipitation ( $\mathrm{mm} \mathrm{day}^{-1}$; dotted-dashed line). The correlation coefficient between the two time series is shown in each panel. The numbers in parentheses indicate the correlations corresponding to the $95 \%$ significance level for each model.

emphasized the large scatter among the ensemble members of their forced atmospheric simulations, indicating that the SST forcing is only part of the story. More recently, Hoerling et al. (2009) have examined the influence of SST on twentieth-century droughts in the northern and southern plains separately, using both observations and a large ensemble of atmospheric simulations performed with three different atmospheric general circulation models. Their results support the conclusion that the causes for droughts in the two regions may be different, with the southern plains conditions being more likely influenced by SST forcing, primarily in the Pacific, and the northern plains droughts being mostly associated with internal atmospheric variability, thus presenting a lower degree of predictability. Further studies are needed to better quantify the influence of SST and the degree of predictability of North American droughts at a more regional scale.

Acknowledgments. We acknowledge the international modeling groups for providing their data for analysis, the Program for Climate Model Diagnosis and Intercomparison (PCMDI) for collecting and archiving the model data, the JSC/CLIVAR Working Group on Coupled Modelling (WGCM) and their Coupled Model Intercomparison Project (CMIP) and Climate Simulation Panel for organizing the model data analysis activity, and the IPCC WG1 TSU for technical support. The IPCC Data Archive at Lawrence Livermore National Laboratory is supported by the Office of Science, US Department of Energy. Funding for AC was provided by NOAA through the U.S. CLIVAR Droughts in Coupled Models 
Project (DRICOMP) and through CDEP funding to ESRL. Insightful conversations with Clara Deser, as well as constructive criticism and suggestions from the NOAA/ ESRL/PSD Attribution Group, in particular Martin Hoerling, Judith Perlwitz, Klaus Wolter, and Dezheng Sun, are gratefully acknowledged.

\section{REFERENCES}

Alexander, M. A., and Coauthors, 2006: Extratropical atmosphereocean variability in CCSM3. J. Climate, 19, 2496-2525.

Arblaster, J. M., G. A. Meehl, and A. Moore, 2002: Interdecadal modulation of Australian rainfall. Climate Dyn., 18, 519-531.

Benson, L., M. S. Berry, E. A. Jolie, J. D. Spangler, D. W. Stahle, and E. M. Hatton, 2007: Possible impacts of early-11th-, middle-12th-, and late-13th-century droughts on western Native Americans and the Mississippian Cahokians. Quat. Sci. Rev., 26, 336-350.

Cook, E. R., C. Woodhouse, C. M. Eakin, D. M. Meko, and D. W. Stahle, 2004: Long term aridity changes in the western United States. Science, 306, 1015-1018.

Dillehay, T. D., 1974: Late Quaternary bison population changes in the southern plains. Plains Anthropol., 19, 180-196.

Douglass, A. E., 1929: The secrets of the southwest solved by talkative tree rings. Natl. Geogr. Mag., 54, 737-770.

, 1935: Dating Pueblo Bonito and other ruins of the southwest. Tech. Rep. Pueblo Bonito series 1, National Geographic Society, 74 pp.

Herweijer, C., R. Seager, and E. R. Cook, 2007: North American droughts of the last millennium from a gridded network of tree ring data. J. Climate, 20, 1353-1379.

Hoerling, M. P., and A. Kumar, 2003: The perfect ocean for drought. Science, 299, 691-694.

_ X.-W. Quan, and J. Eischeid, 2009: Distinct causes for two principal U.S. droughts of the 20th century. Geophys. Res. Lett., 36, L19708, doi:10.1029/2009GL039860.

Jones, T. L., G. M. Brown, L. M. Raab, J. L. McVickar, W. G. Spaulding, D. J. Kennett, A. York, and P. L. Walker, 1999: Environmental imperatives reconsidered. Curr. Anthropol., 40, 137-170.

Kwon, Y.-H., and C. Deser, 2007: North Pacific decadal variability in the Community Climate System Model version 2. J. Climate, 20, 2416-2433.
Liang, X.-Z., J. Zhu, K. E. Kunkel, M. Ting, and J. X. L. Wang, 2008: Do CGCMs simulate the North American Monsoon precipitation seasonal-interannual variability? J. Climate, 21, 4424-4448.

Lu, J., G. Chen, and D. M. W. Frierson, 2008: Response of the zonal mean atmospheric circulation to El Niño versus global warming. J. Climate, 21, 5835-5851.

Mantua, N. J., S. R. Hare, Y. Zhang, J. M. Wallace, and R. C. Francis, 1997: A Pacific interdecadal oscillation with impacts on salmon production. Bull. Amer. Meteor. Soc., 78, 1069-1079.

Meehl, G. A., and A. Hu, 2006: Megadroughts in the Indian monsoon region and southwest North America and a mechanism for associated multidecadal Pacific sea surface temperature anomalies. J. Climate, 19, 1605-1623.

Power, S., T. Casey, C. Folland, A. Colman, and V. Metha, 1999: Interdecadal modulation of the impact of ENSO on Australia. Climate Dyn., 15, 319-324.

Schubert, S. D., M. J. Suarez, P. J. Pegion, R. D. Koster, and J. T. Bacmeister, 2004a: Causes of long-term drought in the United States Great Plains. J. Climate, 17, 485-503.

,,$---\frac{1}{-}$, and,$- 2004 \mathrm{~b}$ : On the cause of the 1930s Dust Bowl. Science, 303, 1855-1859.

Seager, R., Y. Kushnir, C. Herweijer, N. Naik, and J. Velez, 2005: Modeling of tropical forcing of persistent droughts and pluvials over western North America: 1856-2000. J. Climate, 18, 4065-4088.

— N. Graham, C. Herweijer, A. L. Gordon, Y. Kushnir, and E. Cook, 2007: Blueprints for Medieval hydroclimate. Quat. Sci. Rev., 26, 2322-2336, doi:10.1016/j.quascirev.2007.04.020.

_ , Y. Kushnir, M. Ting, M. Cane, N. Naik, and J. Miller, 2008: Would advance knowledge of 1930s SSTs have allowed prediction of the Dust Bowl drought? J. Climate, 21, 3261-3281.

Smith, T. M., R. W. Reynolds, T. C. Peterson, and J. Lawrimore, 2008: Improvements to NOAA's historical merged landocean surface temperature analysis (1880-2006). J. Climate, 21, 2283-2296.

Stine, S., 1994: Extreme and persistent drought in California and Patagonia during medieval time. Nature, 369, 546-549.

Ting, M., and H. Wang, 1997: Summertime U.S. precipitation variability and its relation to Pacific sea surface temperature. J. Climate, 10, 1853-1873.

Trenberth, K. E., 1984: Some effects of finite sample size and persistence on meteorological statistics. Part I: Autocorrelations. Mon. Wea. Rev., 112, 2359-2368. 